\title{
O DIREITO A NÃO SER INFORMADO (A PROTEÇÃO PRIVADA DA LIBERDADE DE INFORMAÇÃO NEGATIVA) ${ }^{1}$
}

\author{
THE RIGHT NOT TO BE INFORMED \\ -THE PRIVATE LAW PROTECTION OF THE \\ NEGATIVE FREEDOM OF INFORMATION-
}

JÖRG NEUNER ${ }^{2}$

\begin{abstract}
RESUMO: O direito a não ser informado possui uma importância considerável não apenas no âmbito dos diagnósticos genéticos, mas em todo o direito privado. Além disso, o direito a não ser informado é protegido também constitucionalmente, como uma expressão do direito geral da personalidade.

PALAVRAS-CHAVE: Autodeterminação Informativa; Diagnósticos Genéticos; Proteção das Esferas da Privacidade e Intimidade; Renúncia ao Esclarecimento.
\end{abstract}

\begin{abstract}
The right not to be informed is of considerable importance, not only in the field of genetic diagnostics, but in relation to private law as a whole. Furthermore, as an expression of the general right of personality, it is also protected by the constitution.

KEYWORDS: Informational Self-determination; Genetic Diagnostics; Protection of Privacy; Waiver of Information Requirements.
\end{abstract}

SUMÁRIO: Introdução; I. Nível Constitucional; II. Nível do Direito Delitivo; 1. O Direito Geral da Personalidade; a) Moderação do Suporte Fático; aa) A Transmissão de uma Informação; aaa) Definição de Conhecimento; bbb) Definição de Imissões; bb) A Vontade Contrária do Receptor; cc) A Esfera mais Estreita da Personalidade; aaa) A Invasão da Esfera da Privacidade; bbb) O Desrespeito da Esfera Íntima; b) Ilegalidade; 2. Saúde; 3. Propriedade, Posse; 4. O Direito a uma Empresa Industrial; 5. Direito de Lealdade; 6. Corpo; a) Deveres de Esclarecimento Médico; b) Deveres de Informação Procedimental; III. Âmbito dos Negócios Jurídicos; 1. Deveres de Instrução Notarial; 2. Deveres de Consultoria de Investimentos; 3. Deveres Legais de Conselhos em Seguros; 4. Deveres de Aconselhamentos Legais na Insolvência; 5. Deveres de Informações

\footnotetext{
Artigo recebido em 20.09.2015. Artigo aceito para publicação em 16.01.2016 mediante convite.

${ }^{1}$ Artigo traduzido por Gunnar Nilsson, Mestre em Direito Privado pela PUCRS, Doutorando e Assistente de Professor na Universidade de Augsburg. O tradutor gostaria de agradecer a senhorita Veronika Kriss pela tradução do resumo e sumário para a língua inglesa.

${ }^{2}$ Professor Catedrático de Direito Civil, Direito do Trabalho, Direito Comercial e Filosofia do Direito na Universidade de Augsburg - Alemanha.joerg.neuner@jura.uni-augsburg.de
} 
ao Consumidor; 6. Condições Gerais dos Negócios; 7. Outros Deveres de Informação; a) Interesse na Prestação (Leistungsinteresse); b) Interesses de Integridade; IV. Resumo; Referências Bibliográficas.

CONTENTS: Introduction; I. Constitutional Aspects; II. Tort Law Aspects; 1. General Right of Personality; a) Elements of the Injury; aa) Disclosure of Information; aaa) Distinguishing from Knowledge; bbb) Distinguishing from Immissions; bb) Contrary Will of the Recipient; cc) Strict Private Sphere; aaa) Invasion of Privacy; bbb) Violation of Intimate Sphere; b) Illegality; 2. Health; 3. Ownership, Possession; 4. Right to the Established Business; 5. Fair Trading Law; 6. Bodily Integrity; a) Medical Obligations of Disclosure; b) Informational Duty of Care; III. Contractual Aspects; 1. Nortarial Duty to Instruct; 2. Investment Advisory Duties; 3. Advisory Duties in Insurance Law; 4. Advisory Duties in Insolvency Law; 5. Consumer Information Requirements; 6 . General Terms and Conditions; 7. Other Information Requirements; a) Positive Interest; b) Negative Interest; IV. Summary; Bibliography.

\section{INTRODUÇÃO}

Deveres de informação e de esclarecimento determinam, se, quando, e como as informações devem ser transmitidas. Eles estão entre os mais complexos, intensivos e discutidos temas de todo o direito privado. No entanto, até agora, os interesses contrários têm sido apenas parcialmente discutidos, por exemplo, em que medida existe um "direito a não ser informado", ou mais especificamente, um "direito a não saber". ${ }^{3} \mathrm{O}$ problema é facilmente percebido no direito médico, especialmente nos diagnósticos preditivos, nos quais uma disposição genética pode ser detectada muito antes do início da doença. Exemplo que pode ser mencionado é o do alelo patológico no $4^{\circ}$. Cromossomo, característica da doença de Huntington ${ }^{4}$, uma doença que em geral se manifesta na meia-idade, e após um longo período de enfermidade, termina com um desfecho fatal. ${ }^{5}$ Mostra-se compatível com o direito à autodeterminação e com a proteção da dignidade humana, se os portadores da mutação (genética), ou os seus parentes biológicos ${ }^{6}$, diante de um sofrimento

\footnotetext{
${ }^{3}$ V. especialmente sobre a problemática dos clones, Jonas, Technik, Medizin und Ethik, 1987, p. 162 ss. (192): "Em suma, o produto da clonagem priva, com antecedência, a liberdade, que só pode prosperar sob a proteção do direito a não saber. Mas privar um ser humano da sua liberdade é um crime irremissível (...)."; geral sobre o direito a não saber, Wiese, FS Niederländer, 1991, p. 475 ss.; Taupitz, FS Wiese, 1998, p. 583 ss.; Duttge, DuD 2010, p. 34 ss.; monograficamente Chadwick/Levitt/Schickle, The Right to Know and the Right not to Know, 1998; sobre a liberdade de informação negativa, Fikentscher/Möllers, NJW 1998, p. 1337 ss.; monograficamente Fenchel, Negative Informationsfreiheit, 1997.

${ }^{4}$ A designação mais antiga para a doença (Chorea) de Huntington é coréia hereditária; os primeiros sintomas da doença aparecem, normalmente, entre os 30 e os 50 anos de idade; o posterior processo de sofrimento ocorre entre 15 e 20 anos; v. pormenorizadamente, Roos, Clinical Neurology, in: Bates et al., Huntington's Disease, 4. ed. 2014, p. 25 ss. (30 ss.).

${ }^{5}$ Outros exemplos de diagnósticos genéticos: distrofia muscular do tipo Duchenne/Becker, câncer de mama familiar, fibrose cística (Mukoviszidose).

${ }^{6}$ Caso um neto saiba de sua predisposição genética sobre a doença de Huntington, da qual já sofreu seu avô (materno), pode-se estar certo de que a mãe também é portadora da mutação e seus irmãos possuem $50 \%$ de probabilidade de ser afetados; v. apenas Kay/Fischer/Hayden, Epidemiology, in: Bates et al., Huntington's Disease (v. acima nota de rodapé 2), p. 131 ss. (132).
} 
incurável, sejam informados antes da sua eclosão? Alguns pacientes podem estar realmente interessados em ter um conhecimento prévio da sua predisposição genética, assim podem planejar a sua vida e a vida da nova geração, mas mesmo assim, existem pessoas que preferem um futuro incerto, ou seja, por razões psicológicas preferem não tomar conhecimento de suas predisposições hereditárias ${ }^{7}$, ou de acordo com o ditado: "Ou como deve viver um homem, se ele já não pode mais confiar no fato de que ele é diferente do que ele pensa?". ${ }^{8}$

A pergunta sobre o "não querer saber" não se restringe, entretanto, apenas ao âmbito dos diagnósticos genéticos. Mesmo em cada procedimento médico é inicialmente incerto se o paciente deseja todos os esclarecimentos prévios sobre os riscos e as chances do tratamento. Além disso, a problemática possui uma importância muito geral no direito privado. Para pensar, apenas, nos extensos requisitos de informação e esclarecimento prévios à celebrabração de um contrato, ou anteriores à prestação de determinados serviços. Mesmo o envio de correio eletrônico não solicitado ou material publicitário pertencem a esse contexto. Deve um ator de direito privado deixar-se impor informações, as quais a aquisição do conhecimento é demorado e que ele considere como paternalistas, de estresse psicológico, ou simplesmente indesejáveis?

\section{NÍVEL CONSTITUCIONAL}

Para um estilo e um planejamento de vida autônomo e responsável, o automanejo das informações é essencial. No âmbito constitucional, a autodeterminação informacional, como uma manifestação do direito geral da personalidade, encontra a sua proteção no Art. $2^{\circ}, \S 1^{\circ}$, combinado com o Art. $1^{\circ}$, $\S 1^{\circ}$, da Lei Fundamental. ${ }^{9} \mathrm{O}$ direito à autonomia informacional possui uma dimensão positiva, no sentido de um direito à liberdade da transferência de conhecimento e informação, porém, como outros direitos de liberdade, possui também uma dimensão negativa, no sentido de um direito a não saber e a não der informado. ${ }^{10}$ Por conseguinte, pode-se falar em um "direito

\footnotetext{
${ }^{7}$ Pormenorizado sobre os muitos motivos para não querer saber o status genético, Schröder, Gendiagnostische Gerechtigkeit, 2004, p. 329 ss.

${ }^{8}$ Mann, Joseph und seine Brüder II, 7. Parte Principal, p. 638; v. mais a respeito dessa referência literária transversal em Retzko, Prädiktive Medizin versus ein (Grund-)Recht auf Nichtwissen, 2006, p. 121; além disso, Wiese, FS Niederländer, 1991, p. 475 ss. (475 s.); em Schiller, Kassandra, Vers. 59 s.: "Apenas o equívoco é a vida, e o conhecimento é a morte".

${ }^{9}$ Fundamental, BVerfGE 65, 1 ss. (41 ss.); especialmente sobre o direito ao esclarecimento dos pacientes, Schwill, Aufklärungsverzicht und Patientenautonomie, 2007, p. 284 ss.

${ }^{10}$ Cf. OLG Celle, NJW 2004, p. 449 ss. (450); Di Fabio, in: Maunz/Dürig, GG-Komm., Stand 2013, Art. 2 GG, número de margem 192, Wollenschäger, AöR 138 (2013), p. 161 ss. (169 ss.); Damm, GesR 2013, p. 385 ss. (391); Koppernock, Das Grundrecht auf bioetische Selbstbestimmung, 1997, p. 89 ss.; D. Lorenz, JZ 2005, p. 1121 ss. (1129); Donner/Simon, DÖV 1990, p. 907 ss. (912 s.), com documentação comprobatória adicional; a liberdade de informação negativa também é parcialmente localizada no Art. $5^{\circ}, \S 1^{\circ}$, da LF; cf. BK-GG/Degenhardt, Stand 2008, Art. $5^{\circ}$, $\S \S 1^{\circ}$ e $2^{\circ}$, número de margem 310 s.; pormenorizado Fenchel, Negative Informationsfreiheit (acima, nota de rodapé 1), p. 70 ss., 119 ss., com documentação comprobatória adicional, bem como p. 29 s., com a delimitação ao direito fundamental de renúncia (como renúncia à eficácia da proteção fundamental).
} 
fundamental a não saber"11, de renúncia à informação como um "princípio de asseguração da liberdade"12 13

Entre privados, em regra, esse direito fundamental não justifica uma eficácia imediata perante terceiros (unmittelbare Drittwirkung), ou seja, um direito de defesa, especialmente, nenhuma pretensão omissiva de efeito direto (direkt wirkenden Unterlassungsanspruch). No entanto, a existência dos deveres de proteção constitucionais e a proibição de insuficiência correspondem a essas reivindicações de proteção dos cidadãos. ${ }^{14}$

\section{NÍVEL DO DIREITO DELITIVO}

No direito delitivo, o direito a não ser informado é - no sentido de uma proteção legal contra informações forçadas - manifestação do direito geral da personalidade como "outros direitos", no sentido do § 823 Al. $1^{\circ}$, do BGB, sendo assegurado através de uma (quase) negatória pretenção omissiva, análoga ao $\S 1004$, Al. $1^{\circ}$, frase $1, \mathrm{BGB} .{ }^{15}$ Através da transmissão indesejada de informações podem também, em casos excepcionais, os bens jurídicos como saúde, propriedade e posse serem lesados. O direito a um negócio estabelecido e em funcionamento, de acordo com o § 823, Al. 10, BGB, protege apenas contra intervenções relacionadas aos negócios e não constitui um direito especial do empresário a não ser informado (algo sobre a história da firma). A imposição de uma obrigação de aceitar informações pode, porém, representar uma razoável importunação, no sentido do $\S 7^{\circ}$, UWG.

Dos casos de importunação com informações, como uma expressão do direito a não ser informado, é de se distinguir a renúncia à oferta de informações. Tal renúncia voluntária pode ocorrer tanto em casos de deveres de esclarecimento médicos, como no caso de deveres de informações sobre procedimento, levando-se em consideração o bem jurídico "corpo" no sentido do $\S 823$, Al. $1^{\circ}$, BGB.

\footnotetext{
${ }^{11}$ Lindner, MedR 2007, p. 286 ss. (290); outros falam de um "direito fundamental ao isolamento informacional" ("Grundrecht auf informationelle Abgeschiedenheit"), cf. Taupitz, FS Wiese, 1998, p. 583 ss. (585); Gassner, GesR 2014, p. 558 s. (558).

${ }^{12}$ Simitis, in: Kroker/Dechamps, Information - eine dritte Wirklichkeitsart neben Materie und Geist, 1995, p. 153 ss.; Duttge, DuD 2010, p. 34 ss. (35).

${ }^{13}$ Sobre a proteção do direito a não saber pelo Art. 8 da Convenção Européia de Direitos Humanos (Direito ao respeito da vida privada e familiar), v. mais pormenorizadamente Wollenschläger, AöR 138 (2013), p. 161 ss. (177 s.).

${ }^{14}$ V. a respeito, pormenorizadamente, Canaris, Grundrecht und Privatrecht, 1999, p. 33 ss.; assim como também em: do mesmo autor, Gesammelte Schriften, Vol. I, 2012, p. 639 ss. (666 ss.); Neuner, in: do mesmo autor, Grundrechte und Privatrecht aus rechtsvergleichender Sicht, 2007, p. 159 ss. (168 ss.); especialmente em relação aos deveres de proteção em favor dos recémnascidos nos exames em série (e, especialmente em relação as doenças incuráveis), Hirschl, Rechtliche Aspekte des Neugeborenenscreenings, 2013, p. 51 ss.

${ }^{15}$ Especialmente no setor da saúde, o "direito a não saber" é garantido pelo Art. $10^{\circ}$, § $2^{\circ}$, frase 2 , da Convenção sobre Direitos Humanos e Biomedicina; v. pormenorizadamente Spranger, Recht und Bioethik, 2010, p. 189 s.; a Convenção não foi até o presente momento nem assinada, nem ratificada pela Alemanha, não sendo considerada assim, um direito público interno, de acordo com o Art. 59 , $\S 2^{\circ}$, da LF.
} 


\section{O Direito Geral da Personalidade}

Lesões ao direito geral da personalidade ocorrem tanto no que diz respeito à moderação do suporte fático quanto em relação as particularidades estruturais da ilegalidade.

\section{a) Moderação do Suporte Fático}

Uma intervenção no direito a não ser informado, como uma expressão do direito geral de personalidade, é o compartilhamento de informações das quais o destinatário não gostaria de tomar por conhecimento, e as quais são suscetíveis de afetar a sua esfera mais íntima da personalidade.

\section{aa) A Transmissão de uma Informação}

O conceito de informação é muito amplo. Ele abrange tudo o que pode ser percebido pelos sentidos e transformado pelo espírito. ${ }^{16}$

\section{aaa) Definição de Conhecimento}

O direito especial a não saber possui um suporte fático estreito, e que apenas assume relevância, contanto que a informação divulgada seja verdadeira. ${ }^{17}$ Isto pode ser percebido claramente, no caso de um paciente que apenas toma "conhecimento" da sua doença quando ele realmente sofre da mesma, mas não quando ele está saudável. ${ }^{18}$

Em se tratando de uma informação inoportuna (Fehlinformation), nenhum conhecimento é transmitido, a não ser que tenha causado ou mantido no receptor uma incorreta representação. A indução ao erro pode lesar o direito geral da personalidade, especialmente, se o receptor não gostaria de ter recebido qualquer comunicação. É apenas de se imaginar, o caso de um paciente, que de acordo com o $\S 8^{\circ}$, Al. $1^{\circ}$, GenDG, não consentiu na divulgação dos resultados dos exames, sendo lhe portanto um falso (falscher) diagnóstico genético submetido. Situação semelhante ocorre quando aquele que não deseja receber um anúncio publicitário, pode ter seu sossego prejudicado, se o anúncio contiver uma declaração falsa. Parece adequado, portanto, de uma forma abrangente para a divulgação de "informações", no sentido de uma indiferenciação da verdade das instruções, que uma mensagem sem a necessária precisão do seu conteúdo e sem a transferência de conhecimento, no sentido de esclarecimento seja exigida.

Mesmo com juízos de valor (Werturteilen) e outras avaliações, nenhum conhecimento é transmitido no que diz respeito a fatos verificáveis intersubjetivamente. A manifestação de uma convicção interna pode, contudo, causar irritações semelhantes a uma constatação de fato. Da mesma forma,

\footnotetext{
${ }^{16}$ Cf. Fenchel, Negative Informationsfreiheit (acima, nota de rodapé 1), p. 130, com documentação comprobatória adicional.

${ }^{17}$ Cf. ainda, Taupitz, FS Wiese, 1998, p. 583 ss. (585, 589); Harmann, NJOZ 2010, p. 819 ss. (822); Schwill, Aufklärungsverzicht und Patientenautonomie (acima, nota de rodapé 7), p. 314.

${ }^{18} \mathrm{~V}$. ainda, sobre o conceito de "conhecimento" como "verdadeira opinião com esclarecimento", em uma perspectiva epistemológica tradicional, Hardy/Schamberger, Logik der Philosophie, 2012, p. 219 ss., com documentação comprobatória adicional.
} 
um paciente pode ser muito sobrecarregado, caso a ele forem comunicadas conclusões médicas definitivas de que a sua saúde encontra-se seriamente comprometida. Da mesma forma, não faz nenhuma diferença essencial, quando uma chamada telefônica indesejada falar de um fato trivial, ou emitir um juízo de valor insignificante. Também nisso se aproxima, recorrer não ao "conhecimento", mas a transferência geral de informações.

\section{bbb) Definição de Imissões}

Imissões, no sentido do § 906, Al. 1, frase 1, BGB (gases, odores, calor, ruído, entre outros) em geral, não contêm qualquer informação que necessite um esforço intelectual. Elas passam a ter relevância, principalmente, no caso de um distúrbio da propriedade ou da posse, e não, como uma violação do direito geral da personalidade. Através de sinais de fumaça ou ruídos (falar alto, música, o toque dos sinos da igreja, entre outros) certamente podem também informações ser transmitidas, no entanto - para além dessas exceções - são enumeradas imissões no § 906, Al. 1, frase 1, BGB, que em sua maior parte são fatores de perturbação, sem qualquer conteúdo de informação específica.

Diferentemente, as imissões de ideais são aquelas que, tipicamente, podem afetar os sentidos psíquicos dos vizinhos. Um telhado horrível ou um um muro de jardim desfigurado constituem fatores de importunação, pois todas as informações estéticas apresentadas nessas obras atuam intelectualmente sobre o espectador e determinam a formação de seu juízo. Igualmente, requer-se um processamento psíquico quando atos inadequados, como os que infrinjam o sentimento de decência forem realizados nas propriedades vizinhas visíveis. Até que ponto as imissões de ideais são capazes de justificar uma violação da propriedade, permanece sendo uma controvérsia dogmática ${ }^{19} \mathrm{Em}$ todo o caso, esses efeitos que se dão em razão do conteúdo da informação lesam o direito a não ser informado, como uma expressão do direito geral da personalidade. ${ }^{20}$

\section{bb) A Vontade Contrária do Receptor}

Uma violação do direito a não ser informado ocorre também quando o receptor não queira tomar conhecimento da informação. Nesse caso, o direito da personalidade e a autodetermminação do receptor devem ser respeitados, mesmo que o emissor (da informação) não conhecia a vontade contrária do receptor. $^{21}$ Esse aspecto deve ser analisado, primeiramente, por uma

\footnotetext{
${ }^{19}$ V. além disso, sobre o estado atual do debate, detalhadamente, Staudinger/Gursky, BGB, Neubearbeitung 2012, § 1004, número de margem 76 ss.; MünchKomm/Baldus, BGB, 6. ed., 2013, § 1004, número de margem 132 ss., com vasta documentação comprobatória adicional.

${ }^{20} \mathrm{~V}$. também, sobre potenciais lesões ao direito geral da personalidade pela imissão de ideais, Baur, JZ 1969, p. 432 s. (432 s.); monograficamente Forkel, Immissionsschutz und Persönlichkeitsrecht, 1968.

${ }^{21}$ Opinião diversa Taupitz, FS Wiese 1998, p. 583 ss. (592 s.), o qual postula uma "ativação" defensiva da vontade da pessoa em questão; afirmativo, Soergel/Beater, BGB, 13. ed. 2005, $\S$ 823, Anexo IV, número de margem 70; crítico e contrariamente, com razão, Wollenschläger, AöR 138 (2013), p. 161 ss. (193 s.), com documentação comprobatória adicional.
} 
ponderação, afastando-se em todo caso a ilegalidade. Em todos casos, pode o legislador estabelecer requisitos especiais sobre a declaração de vontade do receptor, como por exemplo, a obrigatoriedade expressa e a forma escrita, de acordo com o $\S 8^{\circ}$, Al. 1, GenDG (combinado com deveres de esclarecimentos e de consultoria especiais, bem como com uma reserva médica). ${ }^{22}$

As cláusulas gerais dos negócios jurídicos, nas quais o cliente declara o seu consentimento com a publicidade por telefone, Email, SMS são ineficazes. Eles levam a ameaças maciças à esfera privada e prejudicam o cliente, portanto, de forma inadequada, no sentido do $\S 307$, Al. 1, frase 1 , BGB. ${ }^{23}$ De resto, a comprovação do consentimento por Email deve se dar, principalmente, em dois estágios, pelo assim denominado procedimento do "double-opt-in", pelo qual na aplicação de um pedido de confirmação, o mesmo precisa ser novamente respondido positivamente. ${ }^{24}$

Para evitar que o consentimento ocorra devido a uma pressão externa indevida, o segurador e o empregador não devem, em regra, pedir a realização de testes genéticos ( $\S \S 18^{\circ}$, Al. $1,19^{\circ}$ e ss., GenDG). ${ }^{25}$ Mesmo assim, devem os exames de contratação, que exigem que o candidato preste esclarecimentos sobre sua disposição de saúde apenas ser feitos restritivamente, levando em consideração os princípios sobre a admissibilidade das perguntas sobre doenças. ${ }^{26}$ Especialmente protegidos são as pessoas sem o dissernimento necessário para consentir, de acordo com o $\S 14^{\circ}$, GenDG, participantes de uma série de exames de acordo com $\S 16^{\circ}$, GenDG ${ }^{27}$, bem como o nascituro, de acordo com o $\S 15^{\circ}$, Al. 2, GenDG, para o qual os exames genéticos, mesmo com o consentimento da gestante não devem ser realizados, se eles tiverem como objetivo identificar alguma doença com base nas características genéticas do feto, as quais apenas devem ser divulgadas após a conclusão do $18^{\circ}$ ano de vida. ${ }^{28}$

\footnotetext{
${ }^{22} \mathrm{~V}$. especialmente sobre as exigências do consentimento, de acordo com a UWG, Fleischer, NJW 2014, p. 2150 ss. (2154 s.).

${ }^{23}$ Cf. BGHZ 141, 124 ss. (127 ss.); BGH, NJW 1999, p. 2279 ss. (2282); OLG Köln, MMR 2009, p. 470 s.

24 Cf. BGH, MMR 2011, p. 662 ss. (mostrador de texto 37); Glossner, in: Münchener Anwaltshandbuch IT-Recht, 3. ed. 2013, número de margem 482 ss.; Heckmann, in: jurisPKInternet, 4. ed. 2014, número de margem 718 ss. (onde também é tratada a problemática sobre em que medida o envio de um "Check-Mail" representa uma forma de publicidade inadmissível).

${ }^{25}$ Cf. BT-Drucks. 16/10532, p. 36; Vossenkuhl, Der Schutz genetischer Daten, 2013, p. 92.

${ }^{26}$ Assim, a doutrina dominante: cf. Riesenhuber, in: BeckOK/DatenSR, Stand 2014, § 32, número de margem 75, com vasta documentação comprobatória adicional; ainda, restritivamente, Bayreuther, NZA 2010, p. 679 ss. (682); no direito público existem regras em favor de terceiros: assim, os candidatos a uma licença para conduzir precisam, de acordo com os $\S \S 11 \mathrm{ss}$., da FeV, de um parecer médico ou médico-psicológico, além de submeter-se a um exame de visão, isso para salvaguardar o interesse das outras pessoas no trânsito; também aquele que não observar as prescrições de trânsito, pode, de acordo com o § 48 StVO, ser obrigado a participar de aulas de segurança de trânsito.

${ }^{27}$ Especialmente em relação aos exames em série em recém nascidos, v. monograficamente Hirschl, Rechtliche Aspekte des Neugeborenenscreenings (acima, nota de rodapé 12).

${ }^{28}$ V. além disso, em pormenores, Kersten, JZ 2011, p. 161 ss. (164 s.).
} 
A extensão do consentimento, e, especialmente, do não consentimento, é determinada por meio de interpretação. Assim, por exemplo, o consentimento médico para a realização de exames de sangue abrange um diagnóstico geral e, em princípio, um teste de HIV, bem como a divulgação do diagnóstico positivo ou negativo. ${ }^{29} \mathrm{O}$ consentimento, de acordo com o $\S 8^{\circ}$, Al. 1, GenDG deve, no entanto, se dar de forma explícita e por escrito, tanto em relação a extensão dos exames genéticos, como em relação a decisão que determina, se, e em que medida o resultado dos exames deve ser divulgado ou destruído. ${ }^{30}$

No entanto, uma especial desconsideração do esclarecimento, como por exemplo, algo sobre um diagnóstico de câncer, não causa qualquer violação do direito a não ser informado. ${ }^{31}$ Neste caso, a transferência da informação, em si, não é indesejável, mas apenas a maneira e o modo da transmissão. Isso também se aplica para o chamado "dano por choque" ("Schockschäden"), através do qual notícias terríveis são apresentadas forçosamente por qualquer pessoa, sendo portanto, o causador inicial do evento de terror também responsável por danos causados a terceiros (por exemplo danos a saúde de membros familiares próximos). Do próprio direito a não saber deve-se diferenciar também as proibições de divulgação de informações (como por exemplo, os deveres de sigilo médico), especialmente em relação aos terceiros, quando esses não devem tomar conhecimento. ${ }^{32}$

\section{cc) A Esfera mais Estreita da Personalidade}

Aquele que informa uma pessoa sobre algo que esta pessoa não gostaria de saber, restringe a liberdade dessa pessoa. Subseqüentemente, em princípio, qualquer comunicação indesejada poderia constituir uma violação do direito a não ser informado. Uma definição ampla do suporte fático poderia dissolver o sistema delitivo do § 823 e ss., BGB, que não protege a liberdade em si, mas apenas algumas facetas individuais dela. ${ }^{33} \mathrm{O} \S 823$, Al. 1, BGB se estende, portanto, apenas à esfera mais estreita da personalidade. ${ }^{34}$ Também no plano constitucional, os pressupostos do suporte fático do direito geral da personalidade possuem contornos mais restritivos do que aqueles previstos para a liberdade geral de ação: eles compreendem apenas violações, "que são suscetíveis de violar a esfera mais estreita da personalidade". ${ }^{35}$ De acordo com a dogmática

\footnotetext{
${ }^{29}$ Cf. LG Magdeburg, BeckRS 2014, 03364; sobre o consentimento em testes de HIV, por meio de condições gerais do negócio, v. Staudinger/Coester, BGB, Neubearbeitung 2013, § 307, número de margem 413, com documentação comprobatória adicional.

${ }^{30}$ Cf. também, BT-Drucks. 16/10532, p. 26; Kern, in: do mesmo autor, GenDG, 2012, § 8, número de margem 7.

${ }^{31}$ Cf. Taupitz, FS Wiese, 1998, p. 583 ss. (590 s.).

${ }^{32}$ Cf. Taupitz, FS Wiese, 1998, p. 583 ss. (591).

${ }^{33} \mathrm{~V}$. em relação ao estreito conceito de liberdade no direito delitivo, apenas, Lorenz, Der Schutz vor dem unerwünschten Vertrag, 1997, p. 389 ss.; Baston-Vogt, Der sachliche Schutzbereich des zivilrechtlichen allgemeinen Persönlichkeitsrechts, 1997, p. 125 ss., com documentação comprobatória adicional.

${ }^{34} \mathrm{Cf}$. Larenz/Canaris, Schuldrecht II/2, 13. ed., § 80 II 6 a (p. 513).

${ }^{35}$ BVerfGE 54, 148 ss. (153), com documentação comprobatória adicional.
} 
constitucional e delitiva, o direito a não ser informado protege a esfera mais estreita da personalidade. Permanece, entretando, relativamente indeterminado o que seria a "esfera mais estreita da personalidade". Moderadamente, dois pontos principais de casos podem ser diferenciados: por um lado a invasão da esfera da privacidade e por outro, o desrespeito da esfera íntima. ${ }^{36}$

\section{aaa) A Invasão da Esfera da Privacidade}

Uma invasão da esfera da privacidade ocorre quando a vontade da pessoa em "ser deixada em paz" for violada de forma significativa. Com razão entende o BVerfG que o indivíduo deve possuir um âmbito autônomo da vida privada, "ao qual o mundo exterior não tenha acesso, e no qual o indivíduo possa ser deixado em paz". ${ }^{37}$ Esse direito é violado quando a moradia, como um retiro privado não for respeitada, como por exemplo, quando material publicitário for depositado na caixa de correio ou enviado. Sobrecarrega-se, assim, o destinatário não apenas com a eliminação de resíduos, mas especialmente, é ignorado o seu interesse protegido em não precisar lidar com a publicidade indesejada. ${ }^{38} \mathrm{O}$ mesmo aplica-se para Emails, ("spanning") e publicidade por telefone ("cold calling"). Ambas formas publicitárias intervém também na esfera da privacidade do destinatário, mesmo que fora do âmbito da moradia, pois ele tem que, mesmo na dúvida, abrir o Email e responder ativamente a chamada telefônica para tomar conhecimento da finalidade promocional. ${ }^{39}$ Além disso, a publicidade por Email ou por telefone podem ser a qualquer momento possíveis, e o receptor constantemente é retirado de seu trabalho anterior. ${ }^{40}$ Um outro caso especialmente penetrante de invasão na protegida esfera da privacidade ocorre quando os familiares da pessoa falecida são contatados durante o período de luto, com a finalidade de obter o seu consentimento para a exploração comercial de substâncias do corpo do falecido. ${ }^{41}$

\footnotetext{
${ }^{36}$ Diferentemente, e, de forma ampla, distingue McGleenan, in: Chadwick/Levitt/Schickle, The Right to know and the Right not to Know (acima, nota de rodapé 1), p. 43 ss. (45 ss.), no âmbito do direito estadudinense, o "right to be let alone" em quarto espécies de casos: 1 . "with respect to the acquisition and dissemination of personal information concerning the individual (... developed in response to unauthorized publication, photography and other media intrusions)"; 2. "with respect to government searches and seizures with invade the sphere of the individual"; 3 . "when one individual's freedom of speech threatens to disrupt another's liberty of thought and space (... developed as a consequence of the unprecedented increase in the number of door to door brush salesman"); 4. "in relation to fundamental personal decisions (... Genetic technology and genetic screening open up an ever greater vista for personal choice.)".

${ }_{37}$ BverfGE 27, 1 ss. (6), com documentação comprobatória adicional; Soergel/Beater (acima, nota de rodapé 19), § 823, Anexo IV, número de margem 75 , fala de um "direito ao isolamento".

${ }^{38}$ Cf. Köhler, in: Köhler/Bornekamm, UWG, 32. ed. 2014, § 7, número de margem 111, com documentação comprobatória adicional.

${ }^{39}$ Cf. LG Berlin, NJW 1998, p. 3208 s. (3209); Redeker, in: do mesmo autor, IT-Recht, 5. ed. 2012, número de margem 1352; v. além disso, sobre os perigos do bloqueio do correio eletrônico, bem como (minimamente) sobre os custos decorrentes, AG Rostock, NJW-RR 2003, p. 1282 s. (1282). ${ }^{40}$ Cf. Köhler, in: Köhler/Bornekamm, UWG, 32. ed. 2014, § 7, número de margem 137 (onde também se refere a visitas domiciliares não solicitadas)

${ }^{41} \mathrm{~V}$. pormenorizadamente, Weitz, Nutzung menschlicher Körpersubstanzen: Verbietet das Recht die Einholung der Erlaubnis?, 2008, p. 17 ss.
} 
Deve ser avaliado de forma diferente a transferência de informação no espaço público, o qual se caracteriza pelo pluralismo e abertura, concorrência e competição, mas que também é influenciado pela arte e cultura. Todo aquele que participa da vida em sociedade deve, portanto, não apenas ter tolerância estética, mas também ser tolerante com contatos sociáveis de terceiros, como por exemplo, publicidade em jornais, ativistas religiosos ou mendigos. O mesmo aplica-se para a música tocada para os pedestres, os gritos das pessoas nos mercados, a distribuição de material publicitário ou outras importunações que devem ser suportadas. ${ }^{42}$ Uma violação do direito de não informar ocorre nos métodos agressivos de publicidade, com perseguição persistente ou situações consideradas factualmente forçadas, nas quais as empresas quase "capturam o auditório" (como no trânsito, salas de espera, etc.) com informações impostas (aufoktroyieren). ${ }^{43}$

$\mathrm{Na}$ imissão de ideais ${ }^{44}$, apenas em situações excepcionais, pode-se falar de uma violação do direito a não informar. Com base nos direitos conflitantes de liberdade de vizinhos, bem como na falta de critérios confiáveis para o que pode ser conceituado como "de mau gosto" ou "imoral", discrição e tolerância são necessários. ${ }^{45}$ No entanto, existem limitações extremas que devem ser observadas mesmo entre vizinhos. Do conceito de material opinativo bizarro na jurisprudência destacou-se apenas o caso, no qual um vizinho erigiu na divisa de seu terreno uma forca, na qual pendia um boneco com uma placa com a descrição "eu era um babaca". ${ }^{46}$

\section{bbb) O Desrespeito da Esfera Íntima}

Diferentemente da invasão da esfera da privacidade, o desrespeito da esfera da intimidade ocorre quando a informação divulgada comover o receptor de uma forma existencial. Não se trata de um indesejado "overload" de informações, ou de "ser deixado em paz", mas sim, de uma confrontação com fatos que são adequados a atingir o núcleo da personalidade, e que são aptos a provocar uma forte angústia espiritual e emocional. ${ }^{47}$ Comparado à esfera da privacidade, a esfera da intimidade merece uma proteção especial.

\footnotetext{
42 Cf. apenas Baston-Vogt, Der sachliche Schutzbereich des zivilrechtlichen allgemeinen Persönlichkeitsrechts (acima, nota de rodapé 31), p. 468.

${ }^{43}$ V. sobre a doutrina americana da "Captive Audience Doctrine", pormenorizadamente, Fenchel, Negative Informationsfreiheit (acima, nota de rodapé 1), p. 101 ss., com documentação comprobatória adicional.

${ }^{44} \mathrm{~V}$. acima no texto, junto à nota de rodapé $17 \mathrm{~s}$.

${ }^{45}$ Cf. ainda Staudiger/Gursky (acima, nota de rodapé 17), § 1004, número de margem 78; BastonVogt, Der sachliche Schutzbereich des zivilrechtlichen allgemeinen Persönlichkeitsrechts (acima, nota de rodapé 31), p. $469 \mathrm{~s}$.

${ }^{46}$ LG Limburg, NJW-RR 1987, p. 81; v. também, MünchKomm/Baldus (acima, nota de rodapé 17), $\S 1004$, número de margem 132.

${ }^{47}$ Sobre o desenvolvimento histórico, no qual, a verdade adequada, a indiscrição não praticada em público não era considerada uma lesão (Injurie) e deveria ser propagada, Ehmann, AcP 188 (1988), p. 230 ss. (240 ss.).
} 
A esfera da intimidade não é apenas desrespeitada quando dados extremamente pessoais são transferidos externamente de forma ilícita e divulgados para o público, mas também, de forma inversa, ou seja internamente, quando esses mesmos dados são transmitidos sem permissão do titular do direito. Uma avaliação moderada para ambas as constelações demonstra que terceiros divulgam dados confidenciais os quais tocam a esfera interior da personalidade. Que tais dados de caráter mais pessoal, em princípio, somente podem ser divulgados com o consentimento (presumido) da pessoa em causa, é demonstrado igualmente na regra do $\S 10^{\circ}$, Al. 3, frase 4, GenDG. A regra do artigo anterior determina que o médico deve recomendar ao seu paciente que este sugira um aconselhamento genético aos seus familiares ${ }^{48}$, caso for detectada alguma doença tratável sobre a qual os portadores da mutação, em caso de dúvida, queiram ser informados em tempo hábil, pois então terão boas chances de cura. ${ }^{49} \mathrm{Em}$ termos gerais, essa é uma legítima expressão da presunção "in dubio pro vita". Por outro lado, em se tratando de uma doença incurável, o médico não deve, no sentido inverso do $\S 10^{\circ}, \mathrm{Al}$. 3 , frase 4, GenDG, manifestar qualquer recomendação. ${ }^{50}$

A circunstância na qual um paciente pode falar livremente sobre a sua doença hereditária com os seus familiares, com os quais ele constrói uma comunidade de vida e de educação, e os quais ele deve esclarecer, não altera a necessidade fundamental de proteger a sua família contra informações forçadas de terceiros. Estranhos não foram autorizados constitucionalmente a interferir nos assuntos internos da família (Familieninterna) e não devem, certamente, falar e agir como "mensageiros da desgraça" ("Hiobsboten").

Esse direito a não ser informado para proteção da esfera íntima, abrange, por um lado, informações da própria pessoa interessada, as quais ela própria não gostaria de saber. Primeiramente, apenas para refletir, predisposições genéticas ou doenças físicas, mas também experiências traumáticas que foram assimiladas. ${ }^{51}$ Mesmo assim, não compete a terceiros desinteressados "esclarecer" uma criança de que os seus pais, ou um deles (em razão de uma adoção, ou da doação de gametas, ou ainda, de um relacionamento extraconjugal) não são os seus pais biológicos.

A esfera íntima pode ainda ser violada por informações indesejadas que afetam terceiros íntimos. ${ }^{52}$ Assim, podem os pais ficar fortemente carregados

\footnotetext{
${ }^{48} \mathrm{~V}$. essa determinação também abaixo no texto, junto à nota de rodapé 61.

${ }^{49}$ As cláusulas de confidencialidade do $\S 11^{\circ}$, Al. 3, GenDG, pelas quais o médico somente deve divulgar o resultado dos exames genéticos da pessoa em causa, para terceiros, com o seu consentimento explícito e por escrito agravam o sigilo médico em relação aos pacientes; v. Damm, MedR 2014, p. 139 ss. (142), com documentação comprobatória adicional.

${ }^{50}$ Cf. ainda Heyers, MedR 2009, p. 507 ss. (509): "no caso de doenças não tratáveis, a primazia absoluta (do direito a não saber)"; posição contrária, Katzenmeier/Voigt, JZ 2014, p. 900 ss. (901).

${ }^{51} \mathrm{O}$ direito a não ser informado apresenta-se, neste ponto, paralelamente ao direito (ao próprio) esquecimento; v. por último, de forma geral, EuGH, "Google./.Gonzáles", d. 13.5.2014 C-131/12 (ainda não presente na coletânea de decisões - Slg.)

${ }^{52}$ Opinião diversa BGH, NJW 2014, p. 2190 ss. (mostrador de texto 13 ss.)
} 
de culpa, quando eles, em razão de um esclarecimento não solicitado de uma doença própria, puderem causar um (potencial) sofrimento irreversível aos seus filhos. ${ }^{53} \mathrm{O}$ mesmo se aplica na situação inversa, quando um dos pais quer manter em segredo uma doença grave, ou seja, não quer comunicar aos seus familiares, e, um terceiro (por exemplo, o médico) repassa a informação da consternação para as crianças. ${ }^{54}$ Nesse caso, além da pessoa doente, também os seus familiares abalados podem ter os seus direitos da personalidade violados, demonstrando uma comparação com a grande responsabilidade por danos de choque causados aos membros da família. O instituto jurídico do contrato com proteção em favor de terceiros abrange, em todos casos, os membros da família próximos, pois, e na medida em que o contratante (Gläubiger) na fórmula de "em prol da acomodação" se responsabiliza. A inclusão de familiares próximos deve ser analisada com base no Art. $6^{\circ}, \S 1^{\circ}$, LF, o qual coloca a família sob a proteção especial do Estado. Além disso, também é convincente, sob o aspecto da igualdade de tratamento, e não do limiar de intervenção, que a abertura de uma carta publicitária indesejável ${ }^{55}$, ou a publicação de fotografias da vida quotidiana de pessoas famosas ${ }^{56}$ sejam considerados como uma violação dos direitos da personalidade, entretanto, não uma notícia sobre o preocupante estado de saúde de um membro familiar próximo. Para proteger o lesado de um uso ilimitado (Inanspruchnahme) é (ao lado da verificação da ilegalidade) apenas necessário que se trate de familiares próximos e não apenas de terceiros queridos. A informação indesejada não precisa, necessariamente, ser sobre o estado de saúde, mas pode, por exemplo, ser uma indicação especial chocante até então desconhecida da vida de um familiar. Tais critérios legais para uma intervenção no direito a não ser informado através de informações íntimas sobre terceiros próximos somente podem ser considerados em casos especiais. Então, não pode tratar-se de qualquer indiscrição, a qual pode encontrar a sua punição legal ou neutralização. "Quem é indiscreto viola os bons costumes da vida, e os bons costumes irão julgá-lo". ${ }^{57}$

A esfera íntima pode, por fim, também ser afetada por informações de caráter geral, quando estas violarem de forma maciça a sensibilidade moral e

\footnotetext{
${ }^{53}$ Sobre uma sobrecarga do companheiro, que as vezes é mais afetado que o próprio examinando, v. Hirschl, Rechtliche Aspekte des Neugeborenenscreenings (acima, nota de rodapé 12), p. 152, com documentação comprobatória adicional.

${ }^{54}$ V. também Taupitz, FS Wiese, 1998, p. 583 ss. (595), com o exemplo no qual o familiar de um falecido não quer saber as exatas circunstâncias da sua morte, bem como o tipo de lesão.

${ }^{55} \mathrm{~V}$. mais a respeito e pormenores abaixo no texto, junto à nota de rodapé 66 .

${ }^{56} \mathrm{~V}$. apenas EGMR, NJW 2004, p. 2647 ss.

${ }^{57}$ Kohler, Archiv für bürgerliches Recht VII (1893), p. 94 ss. (104); de modo aproximado, Ehmann, AcP 188 (1988), p. 230 ss. (333): "Claro que a falta de tato (Taktlosigkeiten) e as vezes, inclusive, até a pior patifaria (üble Schurkerei) podem levar as informações de um âmbito para o outro; assim não devem as crianças ser informadas muito cedo sobre o comportamento escolar do pai e, por vezes, também sobre as suas atividades políticas e outras do passado. Mas as sanções para a falta de tato (Taktlosigkeiten) e patifaria (Schurkereien) em geral devem ser deixados à moral e aos bons costumes".
} 
estética do destinatário. Tal violação pode se dar, por exemplo, por imagens obscenas, palavras ou ações. "Fotos chocantes" ou outras semelhantes também podem interferir na esfera íntima.

\section{b) Ilegalidade}

A doutrina majoritária classifica o direito geral da personalidade como "direito quadro" ("Rahmenrecht"), para o qual a ilegalidade não é indiciária, e para a qual uma ponderação em cada caso é recomendada. ${ }^{58} \mathrm{Se}$, e em que medida uma ponderação de interesses é necessária depende, no entanto, da natureza da agressão. ${ }^{59}$

Um ato ilícito pode ser desde o início eliminado, quando o destinatário tiver o dever de tomá-lo por conhecimento. ${ }^{60}$ Isso pode resultar, por exemplo, do $\S 16^{\circ}$, da Lei de proteção contra infecções (IfSG), que visa evitar perigos iminentes de uma doença transmissível. Também os pais, os tutores e os assistentes têm a obrigação de levar essas relevantes informações em consideração para o bem-estar da criança ou do assistido. ${ }^{61}$ As mulheres grávidas podem, no entanto, recusar-se a realizar um diagnóstico pré-natal $(P N D) .{ }^{62}$ Também nas informações sem dimensão existencial faltam os critérios tipicamente legais que caracterizam uma invasão da esfera da intimidade.

Além disso, fica excluída a ilegalidade, se o legislador recomenda que terceiros sejam informados, como no caso do $\S 10^{\circ}$, Al. 3, frase 4 da GenDG ${ }^{63}$ : "Deve-se presumir também que os parentes genéticos da pessoa em causa são portadores de traços genéticos que possam ser examinados e preveníveis ou tratáveis para a doença ou distúrbio de saúde; nesse caso, o aconselhamento genético também inclui a recomendação para indicar aconselhamento genético desses parentes". Essa disposição não atinge o direito de liberdade informativa negativa dos parentes, pois o médico tem para com eles o direito e o dever de informar. ${ }^{64}$ O direito a não ser informado pode ser violado, quando o paciente tiver o dever de recomendar aos seus parentes um aconselhamento genético. Tal recomendação não é obrigatória e possui um

\footnotetext{
${ }^{58}$ Cf. apenas BGHZ 198, s. 346 ss. (mostrador de texto 10); BGH, JZ 2004, p. 622 ss. (623); MünchKomm/Wagner, BGB, 6. ed. 2013, § 823, número de margem 242, com documentação comprobatória adicional.

${ }^{59}$ Cf. Larenz/Canaris, Schuldrecht II/2 (acima, nota de rodapé 32), § 80 II (p. 498), com documentação comprobatória adicional.

${ }^{60}$ Cf. ainda Taupitz, FS Wiese, 1998, p. 583 ss. (599 ss.).

${ }^{61}$ No âmbito do Direito Penal, essa regra diz respeito, especialmente, ao aborto não punitivo, de acordo com o § 218a, Al. 4, frase 1, conjugado com $\S 218$ do StGB, o qual nos termos do $\S 219$ StGB pressupõe uma consulta; na qual não pode ser exigido um papel ativo das mulheres grávidas. (cf. Eschelbach, in: BeckOK StGB, Stand 2014, § 219, número de margem 6, com documentação comprobatória adicional), mas, pelo menos, uma participação passiva na forma de ouvir; caso contrário, uma "consulta" não deve realizar-se; contanto que, com isso não seja violado o direito da grávida a não ser informada.

${ }^{62}$ Cf. apenas Duttge, DuD 2010, p. 34 ss. (37), com documentação comprobatória adicional.

${ }^{63} \mathrm{Cf}$. também a regra análoga do § 70, da Lei de Engenharia Genética austríaca.

${ }^{64} \mathrm{~V}$. sobre a problemática constitucional do dever médico de não informar, pormenorizadamente Wollenschläger, AöR 138 (2013), p. 161 ss. (163 ss.).
} 
resultado aberto, mas ela dá razões para que os parentes se preocupem com alguma anomalia genética. Em razão do interesse existencial óbvio dos familiares com os cuidados preventivos da própria saúde, essa determinação parece, no entanto, constitucionalmente indiciária, o que consequentemente não caracteriza nenhum ato ilícito, caso o paciente manifestar legalmente a recomendação de aconselhamento. ${ }^{65}$ Diferentemente deve ser avaliada a situação, quando o paciente previamente souber que um familiar não deseja receber a recomendação, o que sugere uma deliberação.

Valorações legais podem, contrariamente, conduzir a uma indicação da ilegalidade. Isso pode ser facilmente percebido no $\S 8^{\circ}$, Al. 1, combinado com o § 25, Al. 1, número 1, GenDG, no qual a demostração do exame genético sem o consentimento do paciente é, inclusive, ameaçado de pena. Uma importante generalização para a proteção da personalidade no direito civil aparece no $\S 7^{\circ}, U W G^{66}$, o qual, na Al. 2 , número 2 , e número 3 , mencionam que uma importunação pode ser presumida quando: "a publicidade for feita por telefone, sem o devido consentimento prévio do consumidor, ou contra o consentimento ao menos presumido de outros participantes do mercado de consumo", bem como "a publicidade feita por uma máquina de telefonemas ou fax-símile automática, ou o correio eletrônico enviado sem o prévio consentimento expresso do destinatário". ${ }^{67}$ Dessa disposição pode-se concluir, por um lado, que sem o consentimento do destinatário, as mencionadas medidas publicitárias são em princípio, no sentido do § 823, Al. 1, BGB, ilícitas; por outro lado, o mero depósito de material publicitário na caixa de correio não assume indícios de ilegalidade. Entretando, a regra muda, caso o destinatário manifestar a sua vontade, por exemplo, colando um anúncio na caixa de correio, ou manifestar diretamente a sua vontade ao remetente. ${ }^{68}$ Assim, os contatos não difamatórios, somente fundamentam uma violação do direito a não ser informado, em princípio, quando ela for contra a vontade declarada do destinatário. Caso contrário, a liberdade de comunicação seria significativamente prejudicada. ${ }^{69}$ A vontade contrária do destinatário também é irrelevante quando

\footnotetext{
${ }^{65} \mathrm{~V}$. mais a respeito acima no texto, junto à nota de rodapé $46 \mathrm{ss}$.

${ }^{66}$ Sobre a capacidade de generalização, v. também OLG Hamburg, WRP 2012, p. 842 ss. (843), Lg Lüneburg, WRP 2012, p. 365 ss. (366 s.); BGH, GRUR 2009, p. 980 ss. (mostrador de texto 14); Köhler, in: Köhler/Bornekamm, UWG (acima, nota de rodapé 36), § 7, número de margem 14.

${ }^{67} \mathrm{~V}$. especialmente em relação a inadmissibilidade de publicidade não desejada por Email, LG Lübeck, MMR 2009, p. 868, AG Rostock, NJW-RR 2003, p. 1282 s. (1282 s.); LG Berlin, NJW 1998, p. 3208 s. (3209); Fikentscher/Möllers, NJW 1998, p. 1337 ss. (1343); opinião diversa, LG Braunschweig, MMR 2000, p. 50 s. (51); sobre a inadmissibilidade de publicidade por telefone, OLG Frankfurt a. M., NJOZ 2013, p. 162 ss. (163 s.); LG Hamburg, GRUR-RR 2007, p. 61 s. (61); sobre a inadmissibilidade de publicidade via Fax-símile, AG Essen, RDV 1999, p. 174, sobre a inadmissibilidade de publicidade via SMS, LG Berlin, MMR 2003, p. 419 ss. (420 s.).

${ }^{68}$ Cf. LG Lüneburg, WRP 2012, p. 365 ss. (366 ss.); BGHZ 106, p. 229 ss. (232 ss.); Mankowski, WRP 2012, p. 269 ss. (272 ss.); Fenchel, Negative Informationsfreiheit (acima, nota de rodapé a), p. 176 ss., com documentação comprobatória adicional.

${ }^{69}$ Cf. BGH, NJW 2011, p. 1005 ss. (mostrador de texto 8), com documentação comprobatória adicional.
} 
o declarante tiver um legítimo interesse em receber o remetimento, como por exemplo, em uma carta de notificação (mesmo que o destinatário tenha um advogado nomeado). ${ }^{70}$

$\mathrm{Na}$ falta de concretas valorações legais, uma ponderação dos interesses conflitantes se faz necessária. Em relação aos interesses do emissor deve levar-se em consideração, de acordo com o Art. $5^{\circ}, \S 1, L F, 0$ direito fundamental da liberdade de expressão. Levando-se em consideração que tanto a democracia como a sociedade privada dependem de uma "viva" e livre transferência de informações, a carga argumentativa deve ser distribuída, de modo que aquele que quer proibir a difusão da verdade, deve ter uma razão especial para isso. ${ }^{71}$ Esses casos podem, portanto, apenas em circunstâncias excepcionais, como por exemplo, a menoridade ou a enfermidade do destinatário, o motivo injusto ou imoral, o método desonesto de recolhimento de informação, a distância temporal do evento, ou um sofrimento emocional muito grave, fundamentar um veridito de ilegalidade. ${ }^{72}$ Além disso, é importante levar em consideração as alternativas que o destinatário tem de se esquivar, como por exemplo, a glorificação da guerra na literatura da livraria. ${ }^{73}$

No entanto, não há nenhuma alternativa realista para escapar das informações indesejadas, como especialmente ocorre na oferta monopolista, onde prevalecem os interesses individuais (interesses econômicos, a preocupação com a objetividade da informação, o grau de aborrecimento, etc.), onde uma moderação das alternativas de violação deve ser ponderada. ${ }^{74}$

Esboçando a problemática novamente a partir de uma doença grave, a qual é comunicada a um parente próximo, duas constelações podem ser identificadas: primeiramente, pode o portador da mensagem atuar como mero "mensageiro" em relação ao paciente, caso este lhe pedir a transmissão. Caso o paciente não queira a transmissão, a atuação do portador será ilícita, na medida em que o membro da família não queria saber o que o paciente queria ter-Ihe ocultado. Em outros casos (legalmente não especificados), havendo dúvidas se a manifestação foi realizada legitimamente, deve ser feito um sopesamento entre a densidade da sobrecarga e a indicação de uma mensagem (a relação de proximidade, os deveres de cuidado, etc.) com o direito fundamental de liberdade de expressão. A ilegalidade deve, no entanto, ser afirmada, no caso de uma comunicação de um médico, sem fins medicinais, ou mesmo educacionais, sobre uma potencial predisposição da

\footnotetext{
${ }^{70}$ Cf. BGH, NJW 2011, p. 1005 ss. (mostrador de texto 13 s.); crítico, MünchKomm/Baldus (acima, nota de rodapé 17), § 1004, número de margem 105 ss..

${ }_{11} \mathrm{Cf}$. Larenz/Canaris, Schuldrecht II/2 (acima, nota de rodapé 32), § 80 II 5b (p. 509).

${ }^{72} \mathrm{Cf}$. ainda, Larenz/Canaris, Schuldrecht II/2 (acima, nota de rodapé 32), § 80 II 5b (p. 509).

${ }^{73} \mathrm{~V}$. também, BGHZ 64, 178 ss. (183, para escritos pornográficos em um quiosque de uma estação de trem).

${ }^{74}$ V. pormenorizadamente Fenchel, Negative Informationsfreiheit (acima, nota de rodapé 1), p. 157 ss.
} 
doença de Huntington dos próprios filhos, especialmente tendo por base a exorbitante sobrecarga psíquica. ${ }^{75}$

\section{Saúde}

Informações que sobrecarregam o receptor podem não apenas violar o seu direito geral da personalidade como também a sua saúde. Essa lesão passa a ser temida, quando um paciente é submetido a um diagnóstico ruim, do qual ele declaradamente não gostaria de ser informado. Como nas violações do direito geral da personalidade ${ }^{76}$, a comunicação pode também atingir familiares próximos. Uma ilustração encontra-se na decisão Huntington, do $B G H$, do ano de 2014, na qual um médico informou a ex-esposa do paciente sobre o seu diagnóstico (incurável) e sobre os riscos associados em relação aos seus filhos. Desde então, a ex-esposa encontra-se com depressão reativa e em licença médica permanente.

$\mathrm{Na}$ interpretação do $B G H$, a depressão não pode ser legalmente atribuída como responsabilidade do médico. ${ }^{77} \mathrm{O}$ anúncio de uma doença grave se enquadra dentro dos riscos gerais da vida, não encontrando sua proteção nos objetivos do $\S 823$, Al. 1, BGB. Esse argumento muito geral sobre o objetivo de proteção da norma não convence, pois o conhecimento do destino de seus filhos e as dúvidas afligiram tão fortemente a mãe, quanto um conhecimento análogo sobre suas próprias disposições genéticas defeituosas. Uma doença dos filhos enquadra-se nos riscos gerais da vida, mas não que terceiros externos à relação familiar, sem razões substanciais suficientes e, como mensageiros da desgraça, nessa interfiram. A fundamentação nos objetivos de proteção da norma também não convence em termos de consistência, nesse aspecto a jurisprudência ${ }^{78}$ leva em consideração os danos causados por choque aos familiares próximos. ${ }^{79}$ Caso o médico tivesse agido com negligência médica, ou tivesse ele prejudicado o paciente de outra forma, poderia a esposa, que foi informada, fazer valer, em princípio, um relevante dano por choque. Em ambas as constelações, tanto na comunicação da lesão corporal por um lado, como nas informações inoportunas por outro, trata-se de um sofrimento com o qual a esposa do familiar em condição médica grave de saúde tem a sua saúde violada. É irrelevante se o agressor, em uma

\footnotetext{
${ }^{75}$ Opinião contrária em BGH, NJW 2014, p. 2190 ss. (mostrador de texto 13 ss.).

${ }^{76} \mathrm{~V}$. acima no texto, junto à nota de rodapé $50 \mathrm{ss}$.

${ }^{77}$ BGH NJW 2014, p. 2190 ss. (mostrador de texto 9 ss.), crítico, com razão, Gassner, GesR 2014, p. $558 \mathrm{~s}$, o qual também, em princípio afirma os requisitos de um contrato com efeito protetivo em favor de terceiros. A precisa e promenorizada prestação dificilmente estará presente, quando o terceiro não ver a exposição dos perigos de uma interrupção da prestação da mesma forma que o credor. Por um lado, a potencial interrupção da prestação depende da preferência do terceiro em não querer saber, por outro lado, da preferência de discrição do credor. Nesse ponto se diferencia também fundamentalmente a constelação, dos casos de efeitos de atuação de terceiros, como no defeituoso aconselhamento genético e pré-natal. (v. a respeito BGHZ 86, p. 240 ss., 249 s.).

${ }^{78} \mathrm{~V}$. apenas, BGHZ 56, 163 ss.

${ }^{79} \mathrm{~V}$. sobre esse paralelo, acima no texto, após a nota de rodapé 52; também indicado por Damm, MedR 2014, p. 139 ss. (140).
} 
situação similar lesar um terceiro, neste caso, ele responde separadamente. Ambos os casos são semelhantes em seu ponto crucial, ou seja, em ambos uma terrível notícia ilícita é transmitida causando um compreensível dano por choque no destinatário. Os fundamentos da atribuição encontram-se em ambos os casos em comparação, no comportamento prejudicial anterior, o qual viola o direito a não ser informado - em geral e intensionalmente - contra a vontade do destinatário e, portanto, sendo o emissor responsável pelas lesões causadas à saúde. ${ }^{80}$ Ele também não deve ser melhor do que um agressor que, querendo apenas assustar o outro, causa-lhe prejuízos à sua saúde. ${ }^{81}$

De forma análoga à lesão ao direito geral da personalidade no direito ordinário, pode-se falar tanto de uma violação da proteção constitucional da família, bem como da lesão do bem jurídico "saúde" dos familiares próximos. ${ }^{82}$ Para eles aplica-se, em contrapartida, uma antinomia valorativa, como uma sanção para as violações dos direitos da personalidade (colocação indevida de cartas na caixa de correio etc.) que devem ser evitadas e as quais lesam a vítima muito menos do que as violações da saúde. ${ }^{83}$ Com razão, já afirmou o Tribunal de primeira instância OLG Koblenz que, de acordo com o § 823, Al, 1, $\mathrm{BGB}^{84}$, constitui uma violação da saúde, bem como uma ilegalidade, quando o médico (ao contrário do pai adoentado ou do assistente), sem autorização informar terceiros sobre os resultados dos diagnósticos genéticos. ${ }^{85}$

\section{Propriedade, Posse}

A distribuição de informações indesejadas pode - ao lado de pretensões em razão da lesão da saúde, ou do direito geral da personalidade, de acordo com o § 823, Al. 1, BGB - também fundamentar pretensões de deixar de fazer, de remoção, bem como indenização por danos decorrentes da propriedade e da posse. Isso mostra-se de forma especial no envio não autorizado de facsímiles, pois neste caso, através do envio de material, o aparelho de fac-símile imprimirá papéis e utilizará a tinta do Tiner da impressora, sem autorização do destinatário, de forma que o dispositivo pode ser colocado na reivindicação do ato ilícito. ${ }^{86}$ Também a colocação indesejada de material publicitário na caixa de correio viola o direito de propriedade e de posse do proprietário e do possuidor, no caso, do locatário, de acordo com o $§ 823$, Al. 1, BGB. ${ }^{87}$

\footnotetext{
${ }^{80}$ Opinião contrária Katzenmeier/Voigt, JZ 2014, p. 900 ss. (901).

${ }^{81} \mathrm{~V}$. mais sobre essa constelação Larenz/Canaris, Schuldrecht II/2 (acima, nota de rodapé 32), § 76 II $1 \mathrm{~d}$ (S. 379).

${ }^{82} \mathrm{~V}$. pormenorizadamente, acima no texto, após a nota de rodapé $52 \mathrm{ss}$.

${ }^{83} \mathrm{~V}$. pormenorizadamente, acima no texto, junto à nota de rodapé $53 \mathrm{~s}$.

${ }^{84}$ OLG Koblenz, MedR 2014, p. 168 ss. (170 ss.).

${ }^{85}$ Se o médico agiu também culposamente, depende das circunstâncias individuais.

${ }^{86}$ Cf. AG Reinbek, NJOZ 2003, p. 86 s. (86 s.); AG Frankfurt a. M., MMR 2002, p. 490; Köhler, in: Köhler/ Bornekamm, UWG (acima, nota de rodapé 36), § 7, número de margem 195; para a discussão sobre a perda da propriedade através da transmissão de Emails publicitários, v. pormenorizadamente Baetge, NJW 2006, p. 1037 ss. (1038), com documentação comprobatória adicional.

${ }^{87}$ Cf. BGHZ 106, p. 229 ss. (232 ss.); Mankowski, WRP 2012, p. 269 ss. (271), com documentação comprobatória adicional.
} 
No caso de imissões, as quais ao mesmo tempo fornecem informações, podem gerar pretensões tanto em relação a proteção da propriedade como da posse. ${ }^{88}$

\section{O direito a uma empresa industrial (Gewerbebetrieb)}

O direito a uma empresa industrial estabelecida e em funcionamento como um "direito quadro" (Rahmenrecht) no sentido do § 823, Al. 1, BGB, não possui uma relação direta com o direito a não ser informado, nem mesmo pode ser deduzido da garantia constitucional do direito geral da personalidade, conforme previsto no Art. $2^{\circ}$, $\S 1^{\circ}$, combinado com o Art. $1^{\circ}$, $\S 1^{\circ}$, LF. Uma empresa industrial, da mesma forma, não possui uma esfera privada ou íntima. Mesmo que se reconhecer um direito da personalidade do empresário, este abrange apenas o âmbito social, e não o direito a não saber (algo como a história da Firma, ou dados da empresa).

Um paralelo se dá pelo menos, na medida em que o direito de uma empresa estabelecida e em funcionamento orientar-se contra as interferências externas. Da mesma forma como ocorre com as pessoas físicas, a remessa de Emails publicitários, sem o devido consentimento pode caracterizar uma violação do direito da empresa industrial. ${ }^{89} \mathrm{~A}$ remessa de Emails indesejados pode afetar a operação empresarial, causar um trabalho adicional e, eventualmente, acarretar correspondentes custos adicionais. Também chamadas telefônicas com finalidade publicitária podem ser qualificadas como violações ilegais do direito da empresa industrial, caso não forem precedidas do consentimento..$^{90} \mathrm{O}$ mesmo vale para as cartas publicitárias depositadas na caixa de correio da firma contra a vontade expressa dos proprietários da empresa. ${ }^{91}$

\section{Direito de Lealdade}

O direito a não ser informado também é parcialmente protegido pelo direito de lealdade. $\mathrm{O} \S 7^{\circ}$, UWG é de importância central, tratando o assédio indevido dos participantes do mercado como inadmissível. ${ }^{92}$ As pretensões por violação do direito da concorrência, no entanto, podem apenas ser formuladas por concorrentes e pelas associações, conforme previsão do $\S 8^{\circ}$, Al. 3, UWG. O participante do mercado afetado não tem nenhuma pretensão individual decorrente do direito de lealdade. ${ }^{93}$

\footnotetext{
${ }^{88} \mathrm{~V}$. acima no texto, anterior à nota de rodapé 17.

${ }^{89}$ Cf. BGH, NJW 2009, p. 2958 s. (mostrador de texto 11 ss.), especialmente, para o envio não solicitado de "Emails de recomendação" BGH, GRUR 2013, p. 1259 ss.; Spindler, in: BeckOK BGB, Stand 2013, § 823, número de margem 118, com documentação comprobatória adicional.

${ }_{90}$ Cf. Köhler, in: Köhler/Bornekamm, UWG (acima, nota de rodapé 36), § 7, número de margem 119, com documentação comprobatória adicional.

${ }_{91}$ Cf. Mankowski, WRP 2012, p. 269 ss. (271), com documentação comprobatória adicional.

${ }^{92}$ Para um significado geral do $\S 7^{\circ}$. UWG para o direito delitivo, v. a disposição acima no texto, junto à nota de rodapé 64; o § 7 UWG não personifica (com fundamento na regulamentação fechada do § 8 UWG) uma lei protetiva, no sentido do § 823 Al. 2 BGB; cf. Fleischer, NJW 2014, p. 2150 ss. (2150), com documentação comprobatória adicional.

${ }^{3}$ V. pormenorizadamente Köhler, in: Köhler/Bornekamm, UWG (acima, nota de rodapé 36), § 1, número de margem 39; Baetge, NJW 2006, p. 1037 ss. (1038).
} 


\section{Corpo}

O desejo de não receber informações pode não apenas referir-se a importunação, mas também a obtenção de informações necessárias, especialmente deveres de esclarecimento médico e informações de procedimento. Sob esse aspecto, o direito a não ser informado sugere a indagação sobre em que medida o interessado pode renunciar validamente ao esclarecimento.

\section{a) Deveres de Esclarecimento Médico}

A jurisprudência classificada a intervenção médica como uma lesão corporal, no sentido do § 823, Al. 1, BGB, a qual necessita do consentimento e, consequentemente, do adequado esclarecimento médico para tornar-se válida. ${ }^{94}$ De acordo com a opinião contrária, em um procedimento médico lege artis realizado sem o devido esclarecimento, não se está diante de uma lesão à integridade corporal, mas sim, de uma lesão ao direito geral da personalidade. ${ }^{95}$ Apesar da controvérsia sobre o bem jurídico protegido e a potencial reparação por danos causados por déficites de esclarecimento ${ }^{96}$, mostra-se também no fundo problemático, se, e em que medida, um esclarecimento se faz desnecessário, quando o interessado não gostaria de ser informado.

O legislador, nesse aspecto, promulgou, no ano de 2013, os $\S \S 630 \mathrm{c}, \mathrm{Al} .4$, 630 e, Al. 3, BGB, os quais consequentemente possuem aplicação análoga no direito delitivo ${ }^{97}$, o que significa que, além de um esclarecimento terapêutico, um esclarecimento autodeterminativo (Selbstbestimmungsaufkärung) deve ser realizado, caso o paciente "tenha renunciado expressamente a informação adequada". Materialmente é ainda acrescentado e especificado que a renúncia deve se dar de forma expressa "clara e inequívoca". ${ }^{98}$ Esse requisito formal da "inequivocidade" tem a função de esclarecer e advertir, restringindo a autonomia do paciente, ou seja, tornando as declarações que não são determinadas inválidas. Dadas as consequências de longo alcance de uma renúncia ao esclarecimento, essa intervenção marginal na autonomia dos pacientes é adequada ${ }^{99}$ e, levando em consideração as disposições paralelas dos §§ $8^{\circ}$., Al. 1, GenDG, 1904, Al. 5, frase 2 e 1906, Al. 5, frase 1, BGB (entre outros) possuem uma valoração moderadamente consequente.

Obviamente, além disso, a renúncia ao esclarecimento pode colidir com os direitos fundamentais de terceiros, ou ainda, com interesses de bem-estar

\footnotetext{
${ }^{94}$ Cf. apenas BGH, NJW 1980, p. 1905 ss. (1906 s.), com documentação comprobatória adicional.

${ }^{95} \mathrm{~V}$. de forma pormenorizada, Schwill, Aufklärungsverzicht und Patientenautonomie (acima, nota de rodapé 7), p. 251 ss., com documentação comprobatória adicional.

${ }^{96}$ V. pormenorizadamente Janda, JZ 2012, p. 932 ss. (934 ss.) com documentação comprobatória adicional.

${ }_{97} \mathrm{~V}$. sobre a necessária recepção das regras individuais dos §§ 630a e ss. do BGB no direito delitivo, pormenorizadamente Palandt/Sprau, BGB, 74. ed. 2015, § 823, número de margem 144.

${ }^{98}$ BT-Drucks. 17/10488, p. 22.

${ }^{99}$ Cf. apenas BGHZ 29, p. 46 ss. (54); Katzenmeier, in: Laufs/Katzenmeier/Lipp, Arztrecht, 6. ed. 2009, V, número de margem 34.
} 
geral, podendo portanto, não ser permitida ${ }^{100}$ Isso se aplica para o caso de um esclarecimento de um diagnóstico de risco de infecção por HVI, ou ainda, em caso de esclarecimentos de segurança sobre a capacidade de dirigir no trânsito após uma anestesia.

Se mais restrições para a autoproteção dos pacientes são necessárias, ou um Blankoverzicht conforme a máxima "eu não gostaria de saber nada" é permitido, é controverso. Enquanto alguns consideram efetiva uma renúncia completa, de acordo com o princípio da "voluntas aegroti suprema lex" ${ }^{\text {"101, }}$ outros levam em consideração, para a proteção dos pacientes, ao menos um metaesclarecimento (Metaaufklärung), (um esclarecimento sobre o esclarecimento), o qual transmite abstratamente para o paciente que ele tem o direito ao esclarecimento e à renúncia de direitos, ou seja, que lhe seja informado formalmente que ele deve tomar uma decisão. ${ }^{102}$ Os autores da lei, no entanto, incentivam muito mais, ou seja, que o paciente "(deve) tomar conhecimento sobre a necessidade do tratamento, assim como as suas chances e riscos". ${ }^{103}$ Além disso é totalmente inadmissível, tanto para um transplante de órgãos ( $\S 8^{\circ}$, Al. 1, número $\left.1 \mathrm{~b}, T P G\right)$, como para uma castração $\left(\S 3^{\circ}, K a s t r G\right)^{104}$, a renúncia ao esclarecimento. Também no direito civil é reconhecido que não se pode ilimitar completamente um terceiro, por exemplo, através da emissão de uma procuração irrevogável ou geral. ${ }^{105}$ O postulado material pevisto na lei, de que o paciente "(deve) tomar conhecimento sobre as chances e os riscos (do procedimento)", deve ser interpretado restritivamente, para que as legítimas expectativas das pessoas possuam uma correspondência com a redação dos §§ 630c, Al. 4, 630e, Al. 3, $B G B$, de forma que não leve a um desapontamento e não prejudique a expressa previsão do direito a não ser informado. ${ }^{106}$ Portanto, deve o médico chamar a atenção do paciente que tenha uma compreensão, mesmo que de forma abstrata, sobre as oportunidades e os riscos do tratamento, mas não

100 Cf. apenas Harmann, NJOZ 2010, p. 819 ss. (823); Schwill, Aufklärungsverzicht und Patientenautonomie (acima, nota de rodapé 7), p. 338 ss.

${ }^{101}$ Cf. Knauer/Brose, in: Spickhoff, Medizinrecht, 2. ed. 2014, § 223 StGB, número de margem 78; assim como, também, Spickhoff, no local especificado, § 630c, número de margem 45; opinião diversa A. Roßner, NJW 1990, p. 2291 ss. (2294 s.); Harmann, NJOZ 2010, p. 819 ss. (824), com documentação comprobatória adicional.

102 Schwill, Aufklärungsverzicht und Patientenautonomie (acima, nota de rodapé 7), p. 144, 323 s., 351.

${ }^{103}$ BT-Drucks. 17/10488, p. 22 s.

${ }^{104}$ V. pormenorizadamente Golbs, Kastrationsgesetz, 2012, § 3, número de margem 4; Gutmann, in: Schroth/König/Gutmann/Oduncu, Transplantationsgesetz, 2005, § 8 D I 1; v. além disso, sobre a situação jurídica controvertida, de acordo com o $\S 9^{\circ}$. GenDG, Kern, in: do mesmo autor, GenDG (acima, nota de rodapé 28 ), § 9, número de margem 8 , com documentação comprobatória adicional.

${ }^{105} \mathrm{~V}$. pormenorizadamente Wolf/Neuner, Allgemeiner Teil des Bürgerlichen Rechts, 10. ed. 2012, § 10, número de margem 57, com documentação comprobatória adicional.

${ }^{106} \mathrm{~V}$. além disso, sob uma perspectiva metodológica, pormenorizadamente Neuner, Die Rechtsfindung contra legem, 2. ed. 2005, p. 114. 
sobre os detalhes. ${ }^{107} \mathrm{Na}$ prática, deve o médico iniciar a conversa sobre o esclarecimento necessário informando sobre os maiores e menores riscos da intervenção, mas também associando as chances. Essa informação rudimentar é suficiente. A iniciativa subsequente, de renúncia ao esclarecimento pode, então, partir do próprio médico, contanto que ele não abuse do seu agir, oprimindo ou sugerindo uma renúncia ao paciente. ${ }^{108}$

\section{b) Deveres de Informação Procedimental}

Deveres procedimentais podem ter como conteúdo deveres de advertência ou de instrução, os quais servem para advertir outros usuários sobre perigos específicos, ou instruí-los sobre o correto uso dos produtos. Caso o usuário ignore as respectivas advertências ou instruções de uso, assume os riscos do acontecimento, e o obrigado ao procedimento não pode ser responsabilizado pela pretensão de reparação de danos.

Do resultado da desconsideração das instruções, suficientes em si mesmo, deve-se distinguir um outro problema, se os deveres de tráfego de informação são totalmente eliminados e se tornam obsoletos, ou seja, quando o interessado renuncia desde o início cada formulário individual de advertência e instrução. Em todo caso, tal perda dos requisitos de informação deve ser negada, caso terceiros externos ou interesses coletivos forem postos em risco. Neste caso, deve o responsável empreender razoavelmente para que a informação sobre o perigo seja repassada. Contrariamente, caso a iminência de perigo for do titular/destinatário do esclarecimento (Aufklärungsberechtigten), deve se proceder de forma análoga à renúncia do esclarecimento de um paciente, ou seja, devem-lhe ser informados de uma forma geral os riscos, mas não detalhes sobre os concretos potenciais de perigo.

\section{III. ÂMBITO DOS NEGÓCIOS JURÍDICOS}

O princípio da autonomia privada estabelece que as relações jurídicas de direito privado podem ser discutidas e dispostas aleatoriamente e sem condições prévias. ${ }^{109}$ Entretanto, entende-se que para cada obrigação, deve-se possuir um certo conhecimento dos negócios jurídicos, como uma restrição à autonomia privada em sentido formal. No sentido material, a autonomia privada não é estabelecida sem condições prévias, mas sim, depende do conhecimento e competências. ${ }^{110}$ Para garantir decisões autodeterminadas, pode, portanto, ser necessário reduzir os déficites de informação. Para os obrigados a esclarecer (Aufklärungspflichtigen), os requisitos de informação relevantes são concebidos como obrigações de divulgação que são caros e,

\footnotetext{
${ }^{107}$ Cf. Laufs, in: Laufs/Kern, Handbuch des Arztrechts, 4. ed. 2010, § 60, número de margem 18.

${ }^{108}$ Cf. Deutsch, NJW 1983, p. 1351 ss. (1354); Schwill, Aufklärungsverzicht und Patientenautonomie (acima, nota de rodapé 7), p. 146 ss., com documentação comprobatória adicional.

${ }_{109} \mathrm{~V}$. pormenorizadamente Wolf/Neuner, Allgemeiner Teil des Bürgerlichen Rechts (acima, nota de rodapé 103) § 10, número de margem 28 ss., com documentação comprobatória adicional.

${ }^{110} \mathrm{~V}$. também, sobre a diferenciação entre (determinação própria não necessária à autodeterminação) formal e (determinação própria, não heterônoma) material da autonomia privada, Drexl, Die wirtschaftliche Selbstbestimmung des Verbrauchers, 1998, p. 293 ss.
} 
seu âmbito de aplicação (direito político) é controverso. ${ }^{111}$ Levando-se em consideração uma mudança de perspectivas, impõe-se a pergunta, em que medida o titular/destinatário do esclarecimento (Aufklärungsberechtigten) como um potencial beneficiário de informações pode livremente renunciar, fazendo uso do seu "direito a não ser informado". Para o titular/destinatário do esclarecimento podem não apenas o tempo, os custos e momentos de indolência (Trägheitsmomente) desempenhar um papel importante, o que pode ser contraproducente para um excesso de informações. ${ }^{112}$

A mais forte intervenção paternalista encontra-se quando sujeitos de direito privado não apenas devem receber informações passivamente, mas também, tem que processá-las ativamente para realmente alcançar um certo nível de conhecimento. Em casos especiais, a esse dever de conhecimento pode adicionar-se uma "obrigação de informação"113 por parte do obrigado a esclarecer (Aufklärungspflichtigen), que visa assegurar um nível desejado de conhecimento. A menor intervenção paternalista representa todas as informações que o destinatário pode ignorar e, portanto, não exigem a aquisição de conhecimento, ou aquela que ele pode renunciar desde o início.

\section{Deveres de Instrução Notarial}

Declarações de vontade assumen grande importância nos casos de reconhecimento notarial (veja apenas § 311b, Al. 1, BGB, § 15, Al. 3, GmbHG) ${ }^{114}$ O notário deve, de acordo com o $\S 17$, Al. 1, BeurkG: "informar as partes sobre as consequências legais da transação", e certificar para que: "a parte inexperiente envolvida não seja prejudicada". Uma renúncia dessa instrução não é possível. ${ }^{115}$ Trata-se de um dever funcional (Amtspflicht). Uma instrução só é excepcionalmente supérflua, caso uma das partes declare que ela examinou totalmente as consequências jurídicas relevantes e o notário (obrigado a provar) (beweispflichtige) não tiver nenhuma dúvida. ${ }^{116}$ Nessa situação, seria claramente redundante e a finalidade da norma do § 17, Al. 1,

\footnotetext{
${ }^{111}$ V. pormenorizadamente Schön, FS Canaris, Vol. I, 2007, p. 1191 ss. (1193 ss.); Bechtold, Die Grenzen zwingenden Vertragsrechts, 2010, p. 48 ss., com documentação comprobatória adicional. 112 V. pormenorizadamente Eidenmüller, JZ 2005, p. 216 ss. (218); Koch, BKR 2012, p. 485 ss. (485 s.); especialmente sobre novos conhecimentos sobre behavioural finance, detalhadamente Spindler, FS Säcker, 2011, p. 469 ss. (474 ss.); Möllers/Kernchen, ZGR 2011, p. 1 ss. (7 ss., 11 ss.), com documentação comprobatória adicional.

${ }_{113}^{113}$ Grigoleit, in: Bankrechtstag 2012, p. 25 ss. (44).

${ }^{114}$ Enumeração detalhada junto à Wendtland, in: BeckOK BGB, Stand 2014, § 128, número de margem 3; esses requisitos geralmente não se incluem entre os princípios essenciais do direito alemão, de modo que um contrato eficaz firmado sem instrução no exterior é contrário à ordrepublic; cf. apenas, NK-BGB/Bischoff, 2. ed. 2012, § 11 EGBGB, número de margem 15, com vasta documentação comprobatória.

${ }^{115}$ Staudinger/Hertel, BGB, Neubearbeitung 2012, notas preliminares aos §§ 127a e 128, número de margem 497.

${ }^{116}$ Cf. BGH NJW 1995, p. 330 ss.; Litzenburger, in: BeckOK BeurkG, Stand 2014, § 17, número de margem 10, com documentação comprobatória adicional; considerações semelhantes aplicam-se, de acordo com o $\S 2256$ Al. 1, frase 2 , do BGB, ao dever de instrução após a restituição do testamento da custódia oficial.
} 
BeurkG não indica a necessidade (nicht geboten) de que o já "esclarecido" seja novamente "esclarecido". De uma legítima renúncia diferencia-se a constelação na qual não o esclarecimento das partes como tal torna a instrução dispensável, mas sim, sua insensatez evidente a partir da perspectiva do notário.

\section{Deveres de Consultoria de Investimentos}

Nos investimentos em capitais, desde a decisão "Bond-Urteil" do $B G H^{117}$, faz-se uma diferenciação entre obrigações de conselho para satisfazerl justificar o investidor (anlegergerechten) (know your customer) e obrigação de conselho para justificar o objeto (objektgerechten) (know your product). Os requisitos específicos foram melhor esclarecidos e exacerbados a partir de 2011, na decisão "CMS Spread-Ladder-Swap-Urteil"118: "Como parte do aconselhamento justificado aos investidores, o conselheiro deve assegurar a segurança", de modo que "(o cliente) entenda os riscos que a ele foram descritos sobre os produtos financeiros em todos os seus aspectos"119, enquanto que na consulta justificada orientada ao objeto deve-se garantir que: "o cliente tenha em relação aos riscos do negócio, praticamente o mesmo nível de conhecimento e saber do qual possui o banco consultivo". ${ }^{120}$ Estas normas restritas aplicam-se não só para os "pequenos investidores", mas também, pelo contrário, como no caso em questão, em que o autor foi uma empresa média, a qual no passado já havia realizado operações de derivativos semelhantes e foi representada na consultoria pelo banco demandado por um diploma/certificado (Diplom-Volkswirtin) em Economia.

Não é de se estranhar que os bancos reagiram a isso com uma redução de sua escala e retração da consultoria de investimentos. ${ }^{121}$ Do ponto de vista do cliente o extenso modelo de consultoria do mercado de capitais continua a sua disposição, como se ele pudesse se colocar do lado de fora do seu âmbito de aplicação, no qual ele pode, desde o início, dirigir-se com um pedido especificado para o banco, e esse poderá solicitar a mera execução da operação prevista (execution-only-Situation) ${ }^{122}$ Com isso, aos investidores também não são aplicáveis os deveres de esclarecimento, caso eles "tiverem o conhecimento e a experiência suficiente para com as transações propostas ou, não evidenciarem fidedignidade, como experimentados gestores e não desejarem um esclarecimento". ${ }^{123}$ Além disso, resta aos clientes particulares

\footnotetext{
${ }^{117}$ BGHZ 123, p. 126 ss. (1. Diretriz máxima - 1. Leitsatz).

118 BGHZ 189, p. 13 ss.; crítico à respeito, Grigoleit, in: Bamkrechtstag 2012 (acima, nota de rodapé 111$)$, p. $25 \mathrm{ss}$. (29 ss.).

${ }_{119}^{119}$ No local indicado (mostrador de texto 24 ).

${ }^{120}$ No local indicado (mostrador de texto 29).

${ }^{121}$ V. pormenorizadamente Buck-Heeb, WM 2014, p. 385 ss. (387 ss.); do mesmo autor, ZHR 177 (2013), p. 310 ss. (321 ss.), com documentação comprobatória adicional.

${ }_{122}$ Cf. BGHZ 160, p. 50 ss. (mostrador de texto 12); Mülbert/Assmann, in: Assmann/Schneider, WpHG, 6. ed. 2012, nota preliminar ao § 37e, número de margem 24; Grigoleit, ZHR 177 (2013), p. 264 ss. (286), com documentação comprobatória adicional.

${ }^{123}$ BGH NJW 2004, p. 3628 ss. (3629); por último OLG Nürnberg NJW-RR 2013, p. 613; v. além disso MünchKomm/Nobbe/Zahrte, HGB, Vol. VI, 3. ed. 2014, "conselhos de investimento", número
} 
a possibilidade, de acordo com a $\S 31 \mathrm{a}$, Al. 7, WpHG, de poderem ser classificados como clientes profissionais menos vulneráveis. ${ }^{124}$ Significativamente, no entanto, essa classificação exige um exame por parte da empresa de serviços de investimento, nesse caso, se o cliente "devido à sua experiência, conhecimentos e sua especialização" possuia a capacidade de atender a determinados critérios legais de aptidão (§ 31a, Al. 7, frases $2,3, \mathrm{WpHG}){ }^{125}$

\section{Deveres Legais de Conselhos em Seguros}

A lei de contratos de seguros (VVG) define tanto para as seguradoras, como (alternativamente) para os mediadores de seguros (Versicherungsvermittler), diferentes funções de deveres de consultoria. ${ }^{126} \mathrm{O}$ contratante de seguro pode, de acordo com os $\S \S 6^{\circ}$, Al. 3, e 61, Al. 2, VVG ${ }^{127}$ "renunciar o aconselhamento por meio de uma declaração escrita separada, na qual ele declara explicitamente à seguradora (ou aos mediadores de seguros) que a renúncia pode afetar adversamente sua capacidade de ingressar com um pedido de indenização nos termos da Al. 5 (ou § 63) contra a seguradora (ou mediador de seguros)". ${ }^{128}$ O legislador pretende com essa regra seguir o modelo do "consumidor responsável"129, bem como a percepção de que "contra a sua vontade, ninguém (deve) pode se deixar aconselhar e informar". ${ }^{130}$ A proposta do Ombudsmann para excluir os seguros, ao menos aqueles seguros que são existenciais para os cidadãos (seguro de vida, de saúde,

de margem 275; Erman/Kindl, BGB, 14. ed. 2014, § 311, número de margem 78, com documentação comprobatória adicional, sobre o princípio do "sacred right of everybody to make a fool of oneself', aplicável na lei americana de mercado de capitais, remete-se à Lang, Informationspflichten bei Wertpapierdienstleistungen, 2003, § 10, número de margem 19, com documentação comprobatória adicional.

${ }^{124}$ Sobre a discussão em relação à qualificação jurídica dos §§ 31 ss. da WpHG, como únicos requisitos regulamentares com obrigações puramente públicas, BGH WM 2013, p. 1983 ss. (mostrador de texto 15 ss.); Grigoleit, ZHR 177 (2013), p. 264 ss. (270 ss.); Kropf, WM 2014, p. 640 ss. (640 s.), com documentação comprobatória adicional.

125 Sobre as possibilidades de renúncia civil, mas não de regulamentação para a criação de um protocolo de aconselhamento, v. pormenorizadamente Buck-Heeb, ZHR 177 (2013), p. 310 ss. (321), com documentação comprobatória adicional.

${ }^{126}$ V. mais detalhes em Kieninger, AcP 198 (1988), p. 190 ss. (194 ss.); Mattern, Das Informationsmodell im VVG unter Berücksichtigung der Auswirkungen auf die AGB-Kontrolle, 2011, p. 111 ss., com documentação comprobatória adicional.

${ }^{127} \mathrm{~V}$. mais sobre as possibilidades de renúncia do aconselhamento após a conclusão do contrato $\S 6^{\circ}$, Al. 4, frase 2, combinado com frase $1, V V G$, bem como no que diz respeito aos deveres de comunicação do mediador de seguros § 60, Al. 3, combinado com Al. 2, VVG.

${ }^{128}$ A conformidade jurídica dessa determinação em relação ao Direito Europeu é, no que diz respeito à Diretiva relativa à mediação (RL 2002/92/EG) controversa; de modo afirmativo, entre outros, Prölss/Martin, VVG, 28. ed. 2010, § 6, número de margem 38; MünchKomm/Armbrüster, VVG, 2010, § 6, número de margem 165 s.; negando, entre outros, Dörner/Staudinger, WM 2006, p. 1710 ss. (1711).

${ }^{129}$ BT-Drucks. 16/1935, p. 24; afirmativamente, Münkel, in: Rüffer, et. al., VVG, 2. ed. 2011, § 6, número de margem 30; crítico Dörner/Staudinger, WM 2006, p. 1710 ss., com o argumento de que, primeiramente, apenas um consumidor suficientemente informado é um "consumidor responsável".

${ }^{130}$ BT-Drucks. 16/3945, p. 60. 
incapacidade para o trabalho e seguro contra acidentes) ${ }^{131}$, não foi aproveitada. A renúncia pode ter como consequência, por exemplo, que os membros de uma associação de seguro de saúde possam não ter conhecimento dos perigos da rescisão antecipada, caso eles queiram mudar o seguro de saúde privado, mas em razão de uma doença preexistente não forem definitivamente aceitos. ${ }^{132} \mathrm{Na}$ literatura tem sido apontado restritiva e corretamente que uma renúncia não deve ser ao segurado encorajada ou mesmo forçada ${ }^{133}$, sendo ressaltado, ao mesmo tempo, as finesses do treinado vendedor.

Para uma rápida proteção do seguro, pode o segurado, de acordo com o $\S 7^{\circ}$, Al. 1, VVG conjugado com a VVG-Info, renunciar o esclarecimento das informações do contrato, bem como o $A V B$, antes mesmo da sua emissão (Abgabe). ${ }^{135}$ Para isso, é necessário, de acordo com $\S 7^{\circ}$, Al. 1, frase 3 , meiafrase $2, V V G$, um esclarecimento por escrito em separado. ${ }^{136}$ As disposições do $\S 6^{\circ}$, Al. 1 até $\S 5^{\circ}, V V G$, não se aplicam para a consultoria de contratos de grande risco, bem como para o âmbito da venda à distância (Fernabsatzes), de acordo com o § 312c, BGB. ${ }^{137}$ Além disso, deve sempre haver uma razão suficiente para uma consulta, o que depende da vontade expressa do segurado e dos riscos que ele gostaria de assegurar com o seguro. ${ }^{138}$

\section{Deveres de Aconselhamentos Legais na Insolvência}

De acordo com a nova redação do $\S 305$, Al. 1, número 1, InsO, o devedor tem que apresentar um certificado, "que é emitido por uma pessoa ou órgão apropriado, (...) com base em um aconselhamento pessoal". O aconselhamento do devedor é, conforme a interpretação do legislador indispensável "para amparar a abertura de um processo de insolvência", "criar documentos para o Tribunal" (gerichtsfeste Unterlagen), bem como "para evitar o efeito indesejável da porta giratória" (Drehtüreffekt). ${ }^{139}$ Se um devedor quiser desfrutar dos benefícios de um procedimento de insolvência de consumo (Verbraucherinsolvenzverfahren) seguido por uma isenção das

\footnotetext{
${ }^{131}$ Römer, VuR 2007, p. 94 ss. (96).

132 Cf. Römer, VuR 2007, p. 94 ss. (95).

${ }^{133}$ Cf. MünchKomm/Armbrüster (acima, nota de rodapé 126), § 6, número de margem 167; Prölss /Martin, VVG (acima, nota de rodapé 126), § 6, número de margem 42.

${ }^{134}$ Cf. Schwintowski, ZRP 2006, p. 139 ss. (141); Römer, VuR 2007, p. 94 ss. (95).

${ }^{135}$ A conformidade jurídica dessa determinação com o Direito Europeu também é controversa; v. pormenorizadamente MünchKomm/Armbrüster (acima, nota de rodapé 126), § 7, número de margem 83, com documentação comprobatória adicional.

${ }^{136}$ A possibilidade da formulação de uma renúncia é julgada de forma diferente (cf. MünchKomm/ Ambrüster, acima, nota de rodapé 126 , § 7, número de margem 81 , com documentação comprobatória adicional); ela deve ser, consequentemente, negada, assim como, de forma geral, as condições gerais do negócio; v. abaixo no texto, junto à nota de rodapé 147.

${ }^{137}$ Cf. § $6^{\circ}$, Al. 6, VVG; crítico em relação ao âmbito de regulamentação da exceção nos contratos de venda à distância, Ebers, in: Schwintowski/Brömmelmeyer, VVG, 2. ed. 2011, número de margem 54, com documentação comprobatória adicional.

${ }^{138}$ V. pormenorizadamente BT-Drucks. 16/1935, p. 24; Prölss/Martin, VVG (acima, nota de rodapé 126), § 6, número de margem 3 ss.

${ }^{139}$ BT-Drucks. 17/11268, p. 34.
} 
responsabilidades/dívidas legais (Restschuldbefreiung), deve ele portanto, deixar-se aconselhar pessoalmente.

\section{Deveres de Informações ao Consumidor}

Atualmente, os excessivos deveres de informação ao consumidor (veja apenas os $\S \S 312 \mathrm{a}$, Al. 2, frase 1, 312d, BGB combinados com Art. 246, 246a, $\mathrm{e} \mathrm{b}, E G B G B)^{140}$ proporcionam aos consumidores interessados o acesso à informação $0^{141}$, porém não os comprometem com qualquer processamento de informação. A noção de que o consumidor deve tomar por conhecimento o "amontoado" ("Wust") ${ }^{142}$ de informações, inclusive de pouca importância, seria desproporcionado e irrealista (lebensfremd). ${ }^{143}$ As informações também não devem ser obtidas na Internet. ${ }^{144}$ Um Link do Seite de compras que leva o consumidor para o respectivo Seite de informações é suficiente para abrir ao consumidor a opção de conhecimento. Apenas a "Button-Regelung", de acordo com o § 312j, Al. 3, e 4, BGB, exige do consumidor que ele expressamente confirme a sua obrigação de pagar, portanto que ele tome ciência de sua obrigação para não cair em uma armadilha de custos (Kostenfalle). ${ }^{145}$

O consumidor não pode, em princípio, renunciar a disposição de prestação de informações (Zurverfügungstellen). Os §§ 312k, Al. 1 (princípios dos contratos de consumo), 361, Al. 2 (revogação), 487 (contrato de aluguel por tempo parcial), 511 (contrato de empréstimo ao consumidor), BGB, especialmente não permitem um desvio as custas do consumidor. Acresce-se a isso, que o empresário tem o ônus da prova para o cumprimento dos requisitos de informação (veja os §§ 312k, Al. 2, 361 Al. 2, BGB). Além disso, os empresários podem persistir no efeito de estímulo por informações completas, por exemplo, o § $312 \mathrm{a}$, Al. 2, frase 2, BGB, determina que custos de envio somente podem ser exigidos na medida em que o consumidor for corretamente informado. Uma relativização marginal possibilitou o § 312, Al. 1, frase 2, BGB, segundo o qual, para os comprovantes e recibos

140 Pormenorizadamente Wendehorst, NJW 2014, p. 577 ss. (578 ss.); Bülow/Artz, Verbraucherprivatrecht, 4. ed. 2014, número de margem 267 ss.; numa perspectiva do Direito Europeu, Riesenhuber, EU-Vertragsrecht, 2013, § 7, número de margem 16 ss., § 9, número de margem 23 ss.

${ }^{141}$ Para garantir o acesso à informação a forma do texto deve manter, de acordo com o § 126b do BGB, numerosos deveres de informação, ou deve um "suporte duradouro" ser usado, o qual particularmente permite o armazenamento e a reprodução exata da declaração; v. especialmente para as instruções das formas jurídicas de revogação na Internet, BGH NJW 2014, p. 2857 ss.

${ }_{142}$ Nobbe, WM 2011, p. 625 ss.

${ }^{143}$ Cf. ainda, Schulte-Nölke, in: Schulze, et. al., BGB, 8. ed. 2014, § 312d, número de margem 2.

${ }^{144} \mathrm{Cf}$. ainda, Bülow/Artz, Verbraucherprivatrecht (acima, nota de rodapé 138), número de margem 274; Steins, WM 2002, p. 53 ss. (56); Kamanabrou, WM 2000, p. 1417 ss. (1422).

${ }_{145}$ Caso o empresário não atender suficientemente as suas obrigações para a realização da situação da encomenda, de acordo com o § 312j Al. 4 do BGB, nenhum contrato se realiza, embora o § 8 Al. 2 da Diretiva do Consumidor moderadamente, e em sua substância, dispõe que o consumidor não está vinculado ao contrato; v. pormenorizadamente Schulte-Nölke, in: Schulze, et. al. (acima, nota de rodapé 141), § 312d, número de margem 3. 
(Bestätigungen), em vez de papel, pode ser utilizado também um suporte durável de dados, desde que o consumidor tenha concordado.

A indispensabilidade dos protetivos deveres de informação ao consumidor não pode ser contornada, mesmo quando o consumidor simplesmente nega o seu status, fingindo ser um empresário. O conceito de consumidor é determinado objetivamente e, assim como a proteção do consumidor, não está à disposição dos dignos de proteção consumidores aparentes. Pura e simplesmente, os princípios da responsabilidade jurídica pela aparência (Rechtsscheinhaftung), bem como a objeção do abuso de direito (Einwand des Rechtsmissbrauchs), podem ser aplicados, desde que o consumidor atuou contra os contratantes de boa-fé como um empresário. ${ }^{146}$

Os deveres de informação servem, excepcionalmente, a todos os sujeitos de direito privado e não apenas aos consumidores, prevendo a lei, em parte, grandes possibilidades de renúncia para pessoas que não são consumidores. O § 312i, Al. 2, BGB prevê que no comércio eletrônico estão disponíveis, em separado, para essas pessoas, deveres de informação. Entretanto, a lei não faz essa diferenciação de forma consistente. Por exemplo, no que diz respeito aos requisitos de informação do operador turístico, de acordo com o § 651a, Al. 2, BGB, não existe essa diferenciação.

\section{Condições Gerais dos Negócios}

Assim como para as informações ao consumidor, também para as condições gerais do negócio aplica-se o princípio da "legítima ignorância" ${ }^{147}$. Para a inclusão de cláusulas contratuais de $A G B$, somente as condições estabelecidas no § 305, Al. 2, BGB, são obrigatórias (indicação expressa, possibilidade de conhecimento e consentimento do cliente), mas não a efetiva informação das cláusulas individuais. Pois, assim como a experiência transnacional ensina: "No customer in a thousand ever read the conditions (on the back of a parking lot ticket). If he had stopped to do so, he would have missed the train or the boat". ${ }^{48}$

O cliente tem também a oportunidade de renunciar as informações do $A G B$, no sentido do $\S 305$, Al. 2, número 2, BGB. Para esse efeito, um formulário de declaração padrão não é suficiente, mas um acordo individual é permitido, especialmente para celebrar um rápido contrato por telefone, que não leve a uma longa, demorada e desproporcionada conclusão definitiva. ${ }^{149}$

\footnotetext{
146 Cf. MünchKomm/Lorenz, BGB, 6. ed. 2012, § 474, número de margem 23; Herresthal, JZ 2006, p. 695 ss. (700 ss.); Oechsler, FS Canaris, Vol. I, 2007, p. 925 ss. (928 ss.).

${ }^{147}$ Miethaner, AGB-Kontrolle versus Individualvereinbarung, 2010, p. 63 ss.

${ }^{148}$ Lord Denning, Thornton v. Shoe Lane Parking Ltd., (1971), 2 Q.B. p. 163 ss. (169): v. também, Rösler, RabelsZ 73 (2009), p. 889 ss. (900).

${ }^{149}$ Cf. Palandt/Grüneberg (acima, nota de rodapé 95), § 305, número de margem 35; Ulmer/ Habersack, in: Ulmer/Brandner/Hensen, AGB-Recht, 11. ed. 2011, § 305, número de margem 149; MünchKomm/Basedow, BGB, 6. ed. 2012, § 305, número de margem 67, com documentação comprobatória adicional.
} 


\section{Outros Deveres de Informação}

Para outros deveres de informação pré-contratuais, contratuais e póscontratuais, o direito ao não saber deve ser diferentemente avaliado.

\section{a) Interesse na Prestação (Leistungsinteresse)}

No que diz respeito ao interesse na prestação (Leistungsinteresse) ou interesse de equivalência, podem as informações necessárias em si, em princípio, serem renunciadas. Caso alguém comprar, de um outro privado, um $P k w$ usado, sem querer saber dos potenciais defeitos do veículo, perde ele as suas reivindicações de garantia, de acordo com o § 442, Al. 1, frase 2, BGB, mas ele também poderia concordar, desde o início, com uma exclusão da responsabilidade. Do mesmo modo, pode, por exemplo, haver uma renúncia de uma prestação de contas (Rechenschaftserteilung) através do encarregado, de acordo com o $\S 666, \mathrm{BGB}$, ou, sobre a comunicação dos custos estimados de um tratamento, de acordo com o § 630c, Al. 3, frase 1, BGB. ${ }^{150}$ No $\S 1605$, BGB (combinado com o $\S 1580$, frase 2, BGB) é expressamente previsto que as informações sobre a propriedade serão concedidas apenas "quando forem exigidas".

No entanto, é de se considerar que as prescrições essenciais não devem ser contornadas através de declarações de renúncia. Isso se aplica, por exemplo, para as compras de produtos pelo consumidor, de acordo com 0 $\S 475$, Al. 1, frase 2, BGB. A indispensabilidade dessa regra prevista no $\S 475$, Al. 1, fase 2, BGB, não pode ser modificada fundamentalmente por uma fictícia "manifestação de conhecimento" sobre a condição do produto comprado ${ }^{151}$, ou por uma oposição de uma "manifestação de não querer saber".

Além disso, pode ser necessário interpretar restritivamente a manifestação de "não querer saber". Por exemplo, o comprador declara não se interessar pelos defeitos das mercadorias, mas, ao mesmo tempo dá ele expressa ou concludentemente a entender querer usar o objeto de acordo com o convencional, nesse caso, a renúncia abrange, na dúvida, apenas os defeitos que não afetam a capacidade de funcionamento. ${ }^{152}$

\section{b) Interesses de integridade}

Caso as informações sirvam à integridade de interesses, uma renúncia do esclarecimento não pode ser completamente dispensada. O ponto de partida normativo são as novas regras sobre a renúncia de informações ou de esclarecimentos, de acordo com o § 630c, Al. 4,630e, Al. 3, BGB, os quais

\footnotetext{
150 Sobre restrições as possibilidades de renúncia, de acordo com os §§ 138, 242, 307, BGB, v. pormenorizadamente Staudinger/Martinek, BGB, Neubearbeitung 2006, § 666, número de margem 17 ss., com documentação comprobatória adicional.

${ }_{151}$ Cf. apenas Faust, in: BeckOK BGB, Stand 2014, § 475, número de margem 6, com documentação comprobatória adicional.

${ }^{152}$ As regras de exclusão do $\S 276$, Al. 3, BGB, nas quais a responsabilidade por dolo não deve ser emitida com antecedência, não constituem restrições adicionais ao direito a não ser informado, assim, para esses, nenhuma exclusão da responsabilidade é compatível, pois muito mais quer o interessado que o responsável retenha as informações relevantes.
} 
conferem ao médico uma obrigação acessória de pelo menos informar ao paciente disposto a renunciar, as oportunidades e os riscos do tratamento. ${ }^{153}$ Essas disposições referem-se apenas as intervenções médicas, mas em razão da ameaça à integridade de interesses, pode-se concluir que uma renúncia em branco (Blankoverzicht) é inadmissível. Além das necessidades legítimas de proteção contra terceiros, bem como do público em geral, ${ }^{154} \mathrm{a}$ pessoa em causa deve ao menos saber do risco da renúncia da informação na gravidez, para com isso saber sobre o que ela renuncia. Por exemplo, alguém vende um produto defeituoso que está ameaçando a saúde, deve o alienante, em qualquer caso, e mesmo que de forma rudimentar informar, mesmo que o comprador (não especialisado) não deseje as informações. O comprador deve pelo menos, em um meta nível (Metaebene) saber, o que está a sua disposição. Isso também se aplica para a pura perda econômica (reine Vermögensschäden), que o renunciante deve abstratamente levar em conta. O alienante precisa apenas fazer esforços razoáveis, algo sob a forma de uma tentativa repetida de esclarecimento, não possuindo nenhum dever de acréscimo de conhecimento no comprador resistente a conselhos.

\section{RESUMO}

1. O "direito a não saber" possui um âmbito de proteção muito estreito, uma vez que abrange apenas o saber, no sentido de se estender apenas as informações. O conceito indiferentemente verdadeiro de "direito a não ser informado" é mais abrangente e renomeia os interesses dos interessados mais adequadamente.

2. O direito a não ser informado como uma faceta do direito geral da personalidade, no sentido do $\S 823$, Al. 1, BGB, protege tanto contra as ingressões na esfera da privacidade, como também, contra o desprezo da esfera da intimidade.

3. A proteção da esfera da intimidade abrange não apenas os dados extremamente pessoais do interessado em si, mas também aqueles relativos aos parentes próximos. De forma semelhante, pode a saúde, no sentido do $\S 823$, Al. 1, BGB, através da informação dos dados sensíveis dos parentes próximos ser violada.

4. Para determinar a ilegalidade de uma violação do direito a não ser informado, uma ponderação apenas pode ser realizada, se o beneficiário não é obrigado a saber, se o legislador não determina nenhuma recomendação de informação, e caso não existir qualquer indício de ilegalidade.

5. Uma renúncia em branco do dever de informação do médico é inadmissível, a não ser que interesses de terceiros ou de bem-estar gerais pertinentes estejam envolvidos. Também, tendo em vista os interesses de

\footnotetext{
${ }^{153} \mathrm{~V}$. acima no texto, junto à nota de rodapé 105.

${ }^{154} \mathrm{~V}$. também acima no texto, junto à nota de rodapé 98.
} 
integridade, deve o renunciante estar ciente de que as informações a ele fornecidas servem para o esclarecimento dos riscos.

6. Os conceitos jurídicos de cidadãos "responsáveis" são inconsistentes. Eles abrangem desde a exigência paternalista estampada para um tomador de decisões plenamente informado, até um participante do mercado que, - na sequência de uma compreensão puramente formal da autonomia - pode abster-se inteiramente dos conselhos e informações. Particularmente marcantes são os diferentes requisitos para investimentos em capitais, por um lado, e investimentos em seguros, por outro lado. Enquanto para os primeiros, a jurisprudência leva em consideração um "dever de informação", um operador de seguros pode abster-se completamente de conselhos e documentação. Fundamentos materiais suficientes para esta diferenciação categórica não podem ser identificados. ${ }^{155}$

7. Uma renúncia ao fornecimento de informações em geral não é possível, a não ser que os deveres de informação sirvam para remediar uma situação de desiquilíbrio (como ocorre no âmbito do direito do consumidor). Parece contraditório ao legislador, se a parte vulnerável pudesse dispor, ela própria, da proteção a que lhe é destinada. Para os negócios em geral, no entanto, uma renúncia é permitida, como no caso da conclusão do contrato (por telefone) que de outro modo, seria injustificadamente retardada.

8. Um consumidor precisa de informações que sirvam para a otimização de seu conhecimento, e das quais, em regra, não toma por nota. Um processamento de informações obrigatórias seria completamente desproporcionado. Quanto menos informação o consumidor realmente processa, mais se levanta a questão da legitimidade do dever de informar.

\section{REFERÊNCIAS BIBLIOGRÁFICAS}

ARMBRÜSTER, Christian. § 6 und § 7 VVG, In: LANGHEIDT, Theo; WANDT, Manfred (Hrsg.). Münchener Kommentar zum Versicherungsvertragsgesetz: VVG, Band 1: Systematische Darstellungen, Erläuterungen zum EGVVG, §§ 1-99 VVG, 1. Aufl., München: C. H. Beck, 2010.

BAETGE, Dietmar. Unverlangte E-Mail-Werbung zwischen Lauterkeits- und Deliktsrecht, In: NJW 2006, p. 1037 - 1040.

BALDUS, Manfred. § 1004 BGB, In: SÄCKER, Franz J.; RIXECKER, Roland (Hrsg.). Münchener Kommentar zum Bürgerlichen Gesetzbuch: BGB, Band. 6: Sachenrecht, 6. Aufl., München: C. H. Beck, 2013.

\footnotetext{
${ }^{155}$ A posição privilegiada das companhias de seguros não é nova. Apenas para recordar, o inconstitucional alcance da exceção para os contratos de seguro, de acordo com a redação antiga do § 6, número 2, HaustürWG; v. além disso, pormenores em Staudinger/Thüsing, BGB, Neubearbeitung 2012, § 312, número de margem 144, com documentação comprobatória adicional; v. além disso, sobre a necessidade de um sistema de adaptação conforme os deveres de informação e deveres de aconselhamento na conclusão dos contratos de seguro, Kieninger, AcP 198 (1998), p. 190 ss. (207 ss.).
} 
BASEDOW, Jürgen. § 305 BGB, In: SÄCKER, Franz J.; RIXECKER, Roland (Hrsg.). Münchener Kommentar zum Bürgerlichen Gesetzbuch: BGB Band 2: Schuldrecht Allgemeiner Teil, 6. Aufl., München: C. H. Beck, 2012.

BASTON-VOGT, Marion. Der sachliche Schutzbereich des zivilrechtlichen allgemeinen Persönlichkeitsrechts, Tübingen: Mohr Siebeck, 1997.

BAUR, Fritz. Anmerkung BGH, Urteil v. 7.3.1969 - VZR 169/65 (OLG Schleswig), In: JZ 1969, p. 431-433.

BAYREUTHER, Frank. Einstellungsuntersuchungen, Fragerecht und geplantes Beschäftigtendatenschutzgesetz, In: NZA 2010, p. 679-683.

BEATER, Axel. § 823 BGB, In: SOERGEL, Hans Theodor (Hrsg.). BGB, Bürgerliches Gesetzbuch mit Einführungsgesetz und Nebengesetzen, Band 12, 13. Aufl., Stuttgart: Verlag W. Kohlhammer, 2005.

BECHTOLD, Stefan. Die Grenzen zwingenden Vertragsrechts. Tübingen: Mohr Siebeck, 2010.

BISCHOFF, Kai. § 11 EGBGB, In: HEIDEL, Thomas; HÜßTEGE, Rainer; MANSEL, Heinz-Peter; NOACK, Ulrich (Hrsg.). Nomos Kommentar BGB: Allgemeiner Teil, Bd. 1, 2. Aufl., Baden-Baden: Nomos Verlag, 2012.

BUCK-HEEB, Petra. Verhaltenspflichten beim Vertrieb - Zwischen Paternalismus und Schutzlosigkeit der Anleger, In: ZHR 177 (2013), p. 310-343.

. Petra, Vertrieb von Finanzmarktprodukten: Zwischen Outsourcing und beratungsfreiem Geschäft, In: WM 2014 Heft 9, p. 385-396.

BÜLOW, Peter; ARTZ, Markus. Verbraucherprivatrecht, 4. Aufl., Heidelberg: C. F. Müller, 2014.

CANARIS, Claus-Wilhelm. Grundrechte und Privatrecht (Schriftenreihe der Juristischen Gesellschaft zu Berlin, Heft 159), Berlin: Walter de Gruyter, 1999.

, Grundrechte und Privatrecht, In: GRIGOLEIT, Hans Christoph; NEUNER, Jörg (Hrsg.). Gesammelte Schriften Bd. I, Berlin: Walter de Gruyter, 2012.

CHADWICK, Ruth; LEVITT, Mairi; SCHICKLE, Darren. The Right to Know and the Right not to Know: Genetic Privacy and Responsibility, Cambridge: Cambridge University Press, 1998.

COESTER, Michael. § 307, In: STAUDINGER (Hrsg.). Kommentar zum Bürgerlichen Gesetzbuch: Staudinger BGB - Buch 2: Recht der Schuldverhältnisse §§ 305-310; UKlaG (Recht der Allgemeinen Geschäftsbedingungen), Neubearbeitung 2013, Berlin: Sellier de Gruyter, 2013.

DAMM, Reinhard. Prädiktive Gendiagnostik, Familienverband und Haftungsrecht, MedR 32 (2014), p. 139-147.

Reinhard. Prädiktive Diagnostik und Demenz - Rechtliche Grundprobleme und medizinische Optionen, In: GesR 12 (2013), p. 385-399.

DEGENHART, Christoph. Art. 5 Abs. 1 und 2 GG, In: KAHL, Wolfgang; WALDHOFF, Christian; WALTER, Christian (Hrsg.). Bonner Kommentar zum Grundgesetz, Stand 2008, Heidelberg: C. F. Müller, 2008.

DEUTSCH, Erwin. Haftungsfreistellung von Arzt oder Klinik und Verzicht auf Aufklärung durch Unterschrift des Patienten, In: NJW 1983, p. 1351-1354. 
DI FABIO, Udo. Art. 2. GG, In: MAUNZ, Theodor; DÜRIG, Günther (Hrsg.). Grundgesetz Kommentar Band I (art. 1 - 12) Stand 2013, München: C. H. Beck, 2013. DONNER, Hartwig; SIMON, Jürgen. Genomanalyse und Verfassung, In: DÖV 1990, p. 907-918.

DÖRNER, Heinrich; STAUDINGER, Ansgar. Kritische Bemerkungen zum Referentenentwurf eines Gesetzes zur Reform des Versicherungsvertragsrechts, In: WM 2006, Heft 36, p. 1710-1718.

DREXL, Joseph. Die wirtschaftliche Selbstbestimmung des Verbrauchers, Tübingen: Mohr Siebeck, 1998.

DUTTGE, Gunnar. Das Recht auf Nichtwissen in der Medizin, In: DuD 2010, p. 34-38.

EBERS, § 6 VVG, In: SCHWINTOWSKI, Hans Peter; BROMMELMEYER, Christoph (Hrsg.). Praxiskommentar zum Versicherungsvertragsrecht, 2. Aufl., Recklinghausen: ZAP Verlag für die Rechts- und Anwaltspraxis, 2010.

EHMANN, Horst. Informationsschutz und Informationsverkehr im Zivilrecht, In: AcP 188 (1988), p. 230-375.

EIDENMÜLLER, Horst. Der homo oeconomicus und das Schuldrecht: Herausforderungen durch Behavioral Law and Economics, In: JZ/60, 2005, p. 216-224.

ESCHELBACH, Ralf. § 219 StGB. In: VON HEINTSCHEL-HEINEGG, Bernd (Hrsg.). Strafgesetzbuch: StGB Kommentar, 1. Aufl., München: C. H. Beck, 2014.

FAUST, Florian. § 475, In: BAMBERGER, Heinz Georg; ROTH, Herbert (Hrsg.). Beck'scher Online-Kommentar BeurkG, 36. Edition, Stand 2014, München: C. H. Beck, 2014.

FENCHEL, Jörg. Negative Informationsfreiheit: Zugleich ein Beitrag zur negativen Grundrechtsfreiheit, Berlin: Duncker \& Humblot, 1997.

FIKENTSCHER, Wolfgang; MÖLLERS, Thomas M. J. Die (negative) Informationsfreiheit als Grenze von Werbung und Kunstdarbietung, In: NJW 1998, p. 1337-1344.

FLEISCHER, Matthias. Werbefreiheit und rechtliche Zulässigkeit von Werbemaßnahmen, In: NJW 2014, p. 2150-2156.

FORKEL, Hans. Immissionsschutz und Persönlichkeitsrecht, Köln: Carl Heymann Verlag, 1968.

GASSNER, Ulrich. Anmerkung zu BGH, Urt. v. 20.5.2014 - VI ZR 381/13, "Chorea Huntington", In: GesR 2014, p. 558-559.

GLOSSNER, Silke. In: LEUPOLD, Andreas; GLOSSNER; Silke (Hrsg.). Münchener Anwaltshandbuch IT - Recht, 3. Aufl. München: C. H. Beck, 2013.

GRIGOLEIT, Hans Christoph. Anlegerschutz - Produktinformationen und Produktverbote, In: ZHR 177 (2013), p. 264-309.

. Grenzen des Informationsmodells, In: Bankrechtstag 2012, p. 25-64.

GOLBS, Ulrike. Kastrationsgesetz, 1. Aufl., Baden-Baden: Nomos Verlag, 2012.

GRÜNEBERG, Christian. § 305 BGB, In: PALANDT (Hrsg.). Bürgerliches Gesetzbuch Kommentar, 75. Aufl., München: C. H. Beck, 2015.

GURSKY, Karl-Heinz. § 1004 BGB, In: STAUDINGER, J. von (Hrsg.). Kommentar zum Bürgerlichen Gesetzbuch: Staudinger BGB - Buch 3: Sachenrecht §§ 985 - 1011 (Eigentum 3), Neubearbeitung 2012, Berlin: Sellier de Gruyter, 2012. 
GUTMANN, Thomas. § 8, In: SCHROTH, Ulrich; KÖNIG, Peter; GUTMANN, Thomas; ODUNCU, Fuat (Hrsg.). Transplantationsgesetz: TPG Kommentar, München: C. H. Beck, 2005.

HARMANN, Lena. Das Recht des Patienten auf Aufklärungsverzicht, In: NJOZ 2010, p. 819-825.

HARDY, Jörg; SCHAMBERGER, Christoph. Logik der Philosophie: Einführung in die Logik und Argumentationstheorie, Stuttgart: UTB Verlag, 2012.

HECKMANN, Dirk. In: HECKMANN, Dirk (Hrsg.). jurisPK-Internetrecht, 4. Aufl. München: C. H. Beck, 2014.

HEYERS, Johannes. Prädiktive Gesundheitsinformationen - Persönlichkeitsrechte und Drittinteressen - insbesondere am Beispiel der Gendiagnostik bei Abschluß von Privatversicherungen -, In: MedR (2009), p. 507-512.

HERRESTHAL, Carsten. Scheinunternehmer und Scheinverbraucher im BGB, In: JZ, Volume 61, Nummer 14, July 2006, p. 695-707.

HERTEL, Vorbem. zu $\S \S 127 a$ und 128 BGB, In: STAUDINGER, J. von (Hrsg.). Kommentar zum Bürgerlichen Gesetzbuch: Staudinger BGB - Buch 1: Allgemeiner Teil, Neubearbeitung 2012, Berlin: Sellier de Gruyter, 2012.

HIRSCHL, Rechtliche Aspekte des Neugeborenenscreenings. Unter Berücksichtigung des grundrechtlichen Schutzanspruchs des Neugeborenen und besonderer Beachtung des Gendiagnostikgesetzes, Baden-Baden: Nomos Verlag, 2013.

JANDA, Constanze. Der ärztliche Aufklärungsfehler als haftungsrechtliches Problem. Überlegungen zu Schutzgut und Schutzzweck der Einwilligung und den Rechtsfolgen von Aufklärungsmängeln, In: JZ, Volume 67, Nummer 19, October 2012, p. 932-941.

JONAS, Hans. Technik, Medizin und Ethik: Zur Praxis des Prinzips Verantwortung, 8. Auf., Berlin: Suhrkamp Verlag, 1987.

KAMANABROU, Sudabeh. Die Umsetzung der Fernabsatzrichtlinie, In: WM 2000, p. 1417-1426.

KAY, Chris; FISHER, Emily; HAYDEN, Michael R. Epidemiology, In: BATES, Gillian; TABRIZI, Sarah; JONES, Leslie. Huntington's Disease, 4 ed., Oxford: University Press, 2014, p. 131-164.

KATZENMEIER, Christian; VOIGT, Tobias. Anmerkung, In: JZ Volume 69, Nummer 18, September 2014, p. 900-902.

KATZENMEIER, Christian. V. Aufklärungspflicht und Einwilligung, In: LAUFS, Adolf; KATZENMEIER, Christian; LIPP, Volker (Hrsg.). Arztrecht (NJW Praxis Bd. 29), 6. Aufl., München: C. H. Beck, 2009.

KERN, Bernd-Rüdiger. § 8 und § 9, In: KERN Bernd-Rüdiger (Hrsg.). Gendiagnostikgesetz: GenDG Kommentar, München: C. H. Beck, 2012.

KERSTEN, Jens. Die genetische Optimierung des Menschen - Plädoyer für eine Kritik unserer genetischen Vernunft -, In: JZ Volume 66, Nummer 4, Februar 2011, p. 161-168.

KIENINGER, Eva-Maria. Informations-, Aufklärungs- und Beratungspflichten beim Abschluss von Versicherungsverträgen, In: AcP 198 (1998), p. 190-247.

KINDL, Johann. § 311 BGB, In: WESTERMANN, Harm Peter (Hrsg.). Erman, BGBKommentar, 14 Aufl., Köln: Otto Schmidt Verlag, 2014. 
KNAUER, Christoph; BROSE, Johannes, § 223 StGB, In: SPICKHOFF, Andreas (Hrsg.). Medizinrecht, 2. Aufl. München: C. H. Beck, 2014.

$\mathrm{KOCH}$, Jens. Grenzen des informationsbasierten Anlegerschutzes - Die Gratwanderung zwischen angemessener Aufklärung und information overload, In: BKR 2012, p. 485-493.

KOHLER, Josef. Das Recht an Briefen, In: Archiv für bürgerliches Recht, VII, 1893, p. 94-149.

KÖHLER, Helmut. $\S 7$ UWG, In: KÖHLER, Helmut; BORNKAMM, Joachim (Hrsg.). Gesetz gegen den unlauteren Wettbewerb: UWG mit PAngV, UKlaG, DL-InfoV, 32. Aufl., München: C. H. Beck, 2014.

KOPPERNOCK, Martin. Das Grundrecht auf bioethische Selbstbestimmung: zur Rekonstruktion des allgemeinen Persönlichkeitsrechts, Baden-Baden: Nomos Verlag, 1997.

KROPF, Christian. Keine zivilrechtliche Haftung der Banken im beratungsfreien Anlagegeschäft - zugleich Urteilsanmerkung zu BGH v. 17.9.2013 = WM 2013, 1983 -, In: WM 2014, p. 640-644.

LARENZ, Karl; CANARIS; Claus-Wilhelm, Lehrbuch des Schuldrechts, Bd.2/2, Besonderer Teil, 13. Aufl. München: C. H. Beck, 1994.

LAUFS, Adolf. § 60, In: LAUFS, Adolf; KERN, Bernd-Rüdiger (Hrsg.). Handbuch des Arztrechts, 4. Aufl. München: C. H. Beck, 2010.

LINDNER, Joseph Franz. Grundrechtsfragen prädiktiver Gendiagnostik, In: MedR 2007, p. 286-295.

LITZENBURGER, § 17 BeurkG, In: BAMBERGER, Heinz Georg; ROTH, Herbert (Hrsg.). Beck'scher Online-Kommentar BeurkG, 36. Edition, Stand 2014, München: C. H. Beck, 2014.

LORENZ, Dieter. Allgemeines Persönlichkeitsrecht und Gentechnologie, JZ 2005, p. 1121-1129.

LORENZ, Stephan. Der Schutz vor dem unerwünschten Vertrag: Eine Untersuchung von Möglichkeiten und Grenzen der Abschlußkontrolle im geltenden Recht, München: C. H. Beck, 1997.

LORENZ, Stephan. § 474 BGB, In: SÄCKER, Franz J.; RIXECKER, Roland (Hrsg.). Münchener Kommentar zum Bürgerlichen Gesetzbuch: BGB Band 3: Schuldrecht, Besonderer Teil I §§ 433-534, CISG, 6. Aufl., München: C. H. Beck, 2012.

MANN, Thomas. Joseph und seine Brüder II, 5. Aufl., Frankfurt am Main: S. Fischer Verlag, 2007.

MANKOWSKI, Peter. Postwurfsendungen nein danke!, In: WRP 2012, (Heft 3), p. 269-273. MARTINEK, Michael. § 666 BGB, In: STAUDINGER, J. von (Hrsg.). Kommentar zum Bürgerlichen Gesetzbuch: Staudinger BGB - Buch 2: Recht der Schuldverhältnisse §§ 657 - 704 (Geschäftsbesorgung), Neubearbeitung 2006, Berlin: Sellier de Gruyter, 2006.

MATTERN, Isabel. Das Informationsmodell im VVG unter Berücksichtigung der Auswirkungen auf die AGB-Kontrolle, Karlsruhe: Verlag Versicherungswirtschaft, 2011.

MIETHANER, AGB-Kontrolle versus Individualvereinbarung, Tübingen: Mohr Siebeck 2010. MÖLLERS, Thomas M. J.; KERNCHEN, Eva. Information Overload and Kapitalmarkt Plädoyer zur Einführung eines Kurzfinanzberichts auf empirischer, psychologischer und rechtsvergleichender Basis -, In: ZGR/1, 2011, p. 1-26. 
MÜLBERT, Peter; ASSMANN, Heinz-Dieter. Vorbem. zu § 37e, In: ASSMANN, HeinzDieter; SCHNEIDER, Uwe H. (Hrsg.). Wertpapierhandelsgesetz: WpHG Kommentar, 6. Aufl., Köln: Dr. Otto Schmidt Verlag, 2012.

MÜNKEL, Thomas. § 6 VVG, In: RÜFFER, Wilfried; HALBACH, Dirk; SCHIMIKOWSKI, Peter (Hrsg.). Versicherungsvertragsgesetz: VVG Handkommentar, 2. Aufl., BadenBaden: Nomos Verlag, 2011.

NEUNER, Jörg. Die Einwirkung der Grundrechte auf das deutsche Privatrecht, In: NEUNER, Jörg (Hrsg.). Grundrechte und Privatrecht aus rechtsvergleichender Sicht, Tübingen: Mohr Siebeck, 2007, p. 159-176.

Die Rechtsfindung contra legem, 2. Aufl., München: C. H. Beck, 2005.

NOBBE, Gerd. Neuregelungen im Verbraucherkreditrecht - Ein kritischer Überblick -, In: WM 2011 Heft 14, p. 625-632.

NOBBE, Gerd; ZAHRTE, Kai. HBG, In: SCHMIDT, Karsten (Hrsg.). Münchener Kommentar zum Handelsgesetzbuch: HGB, Band 6: Bankvertragsrecht, 3. Aufl., München: C. H. Beck, 2014.

OECHSLER, Jürgen. Vertrauenshaftung von Verbrauchern, In: HELDRICH, Andreas; KOLLER, Ingo; PRÖLSS, Jürgen; LANGENBUCHER, Katja; et. al. (Hrsg.). Festschrift für Claus-Wilhelm Canaris zum 70. Geburtstag, Bd. I, München: C. H. Beck, 2007, p. 925-944.

PRÖLSS, Erich R.; MARTIN, Anton. § 6 VVG, In: PRÖLSS, Erich; MARTIN, Anton et. al. (Hrsg.). Versicherungsvertragsgesetz: VVG mit Nebengesetzen, Vermittlerrecht und Allgemeinen Versicherungsbedingungen, 28. Aufl., München: C. H. Beck, 2010.

REDEKER, Helmut. In: REDEKER, Helmut (Hrsg.). IT-Recht (NJW Praxis Bd. 55), 5. Aufl., München: C. H. Beck, 2012.

RETZKO, Prädiktive Medizin versus ein (Grund-)Recht auf Nichtwissen (Berichte aus der Rechtswissenschaft), Herzogenrath bei Aachen: Schaker Verlag, 2006.

RIESENHUBER, Karl. Europäisches Vertragsrecht, 2. Aufl., Berlin: De Gruyter, 2006.

RIESENHUBER, Karl. § 32 In: Wolff/Brink (Hrsg.). Beck'scher Online-Kommentar Datenschutzrecht, 9. Edition, Stand 2014, München: C. H. Beck, 2014.

RÖMER, Wolfgang. Beratung nötig - Verzicht möglich. Zur Kunst der Gesetzgebung, In: VuR 2007, p. 94-96.

RÖSLER, Hannes. Schutz des Schwächeren im Europäischen Vertragsrecht Typisierte und individuelle Unterlegenheit im Mehrebenenprivatrecht, In: RabelsZ Volume 73, Nummer 4, October 2009, p. 889-911.

ROOS, Raymund A. C.. Clinical Neurology, In: BATES, Gillian; TABRIZI, Sarah; JONES, Leslie. Huntington's Disease, 4 ed., Oxford: University Press, 2014, p. 25-45.

ROßNER, Hans-Jürgen. Verzicht des Patienten auf eine Aufklärung durch den Arzt, In: NJW 1990, p. 2291-2296.

SCHILLER, Friedrich. Kassandra. Disponível em: http://www.friedrich-schiller-archiv.de/ inhaltsangaben/kassandra-inhaltsangabe-quellen-interpretation-schiller/. Acesso em: 24 out. 2015.

SCHÖN, Wolfgang. Zwingendes Recht oder informierte Entscheidung - Zu einer (neuen) Grundlage unserer Zivilrechtsordnung. In: HELDRICH, Andreas; KOLLER, Ingo; PRÖLSS, Jürgen; LANGENBUCHER, Katja; et. al. (Hrsg.). Festschrift für Claus-Wilhelm Canaris zum 70. Geburtstag, Bd. I, München: C. H. Beck, 2007, p. 1191-1212. 
SCHRÖDER, Peter. Gendiagnostische Gerechtigkeit. Eine ethische Studie über die Herausforderungen postnataler genetischer Prädiktion, Berlin: LIT Verlag, 2004.

SCHULTE-NÖLKE, Hans. § 312d BGB, In: SCHULZE, Reiner; DÖRNER, Heinrich; EBERT, Ina; et. al. (Hrsg.). Bürgerliches Gesetzbuch Handkommentar, 8. Aufl., BadenBaden: Nomos Verlag, 2014.

SCHWILL, Florian. Aufklärungsverzicht und Patientenautonomie. Das Recht des Patienten zum Verzicht auf die ärztliche Aufklärung, Marburg: Tectum Verlag, 2007.

SCHWINTOWSKI, Hans-Peter. Neuerungen im Versicherungsvertragsrecht, In: ZRP 2006, p. 139-142.

SIMITIS, Spiros. In: KROKER, Eduard; DECHAMPS, Bruno (Hrsg.). Information - eine dritte Wirklichkeitsart neben Materie und Geist, Frankfurt am Main: Verlag Frankfurter Allgemeine Zeitung, 1995.

SPICKHOFF, Andreas. § 630c BGB, In: SPICKHOFF, Andreas (Hrsg.). Medizinrecht, 2. Aufl. München: C. H. Beck, 2014.

SPINDLER, Gerald. § 823 BGB. In: BAMBERGER, Heinz Georg; ROTH, Herbert (Hrsg.). Kommentar zum Bürgerlichen Gesetzbuch: BGB, 3. Aufl., München: C. H. Beck, 2012.

SPINDLER, Gerald. Anlegerschutz im Kapitalmarkt - und Bankrecht - Neujustierung durch Behavioural Finance?, In: JOOST, Detlev (Hrsg.). Festschrift für Franz Jürgen Säcker zum 70. Geburtstag. München: C. H. Beck, 2011, p. 469-486.

SPRANGER, Tade Mathias. Recht auf Bioethik: Verweisungszusammenhänge bei der Normierung der Lebenswissenschaften, Tübingen: Mohr Siebeck, 2010.

SPRAU, Hartwig. § 823 BGB, In: PALANDT (Hrsg.). Bürgerliches Gesetzbuch, 74. Aufl., München: C. H. Beck, 2015.

STEINS, Clemens Tobias. Entwicklung der Informationspflichten im E-Commerce durch Rechtsprechung und Schuldrechtsreform - Zugleich Anmerkung zum Urteil des OLG München vom 25. Januar 2001 = WM 2001, 2394, In: WM 2002, p. 53-60.

TAUPITZ, Jochen. Das Recht auf Nichtwissen, In: HANAU, Peter; LORENZ, Egon; MATTHES, Hans C. (Hrsg.): Festschrift für Günter Wiese zum 70. Geburtstag, Neuwied; Kriftel: Hermann Luchterhand Verlag (1998).

THÜSING, § 312 BGB, In: STAUDINGER, J. von (Hrsg.). Kommentar zum Bürgerlichen Gesetzbuch: Staudinger BGB - Buch 2: Recht der Schuldverhältnisse §§ 311, 311a, 312, 312a-i, Neubearbeitung 2012, Berlin: Sellier de Gruyter, 2012.

ULMER, Peter; HABERSACK, Mathias. § 305 BGB, In: ULMER, Peter; et. al. (Hrsg.). AGB-Recht: Kommentar zu den $\S \S 305-310$ BGB und zum UKlaG. 1. Aufl., Köln: Dr. Otto Schmidt Verlag, 2011.

VOSSENKUHL, Cosima. Der Schutz genetischer Daten. Unter besonderer Berücksichtigung des Gendiagnostikgesetzes, Berlin: Springer-Verlag, 2013.

WAGNER, Gerhard. § 823 BGB, In: In: SÄCKER, Franz J.; RIXECKER, Roland (Hrsg.). Münchener Kommentar zum Bürgerlichen Gesetzbuch: BGB Band 5: Schuldrecht: Besonderer Teil III §§ 705-853, Partnerschaftsgesellschaftsgesetz, Produkthaftungsgesetz, 6. Aufl., München: C. H. Beck, 2013.

WEITZ, Heinz-Joachim. Nutzung menschlicher Körpersubstanzen: Verbietet das Recht die Einholung der Erlaubnis?, Berlin: LIT Verlag, 2008.

WENDEHORST, Christiane. Das neue Gesetz zur Umsetzung der Verbraucherrechterichtlinie, In: NJW 2014, p. 577-584. 
WENDTLAND, Holger. § 128 BGB, In: BAMBERGER, Heinz Georg; ROTH, Herbert (Hrsg.). Kommentar zum Bürgerlichen Gesetzbuch: BGB: Band 1: §§ $1-610,3$. Aufl., München: C. H. Beck, 2012.

WIESE, Günther. Gibt es ein Recht auf Nichtwissen? - Dargestellt am Beispiel der genetischen Veranlagung von Arbeitnehmern, In: JAYME, Eric (Hrsg.). Festschrift für Hubert Niederländer. Zum siebzigsten Geburtstag am 10. Februar 1991, Heidelberg: Winter Verlag, 1991.

WOLF, Manfred; NEUNER, Jörg. Allgemeiner Teil des Bürgerlichen Rechts, 10. Aufl., München: C. H. Beck, 2012.

WOLLENSCHLÄGER, Ferdinand. Der Drittbezug prädiktiver Gendiagnostik im Spannungsfeld der Grundrechte auf Wissen, Nichtwissen und Geheimhaltung Krankheitsveranlagungen im Familienverbund und das neue Gendiagnostikgesetz, In: AöR Vol. 138 (2013), p. 161-203. 